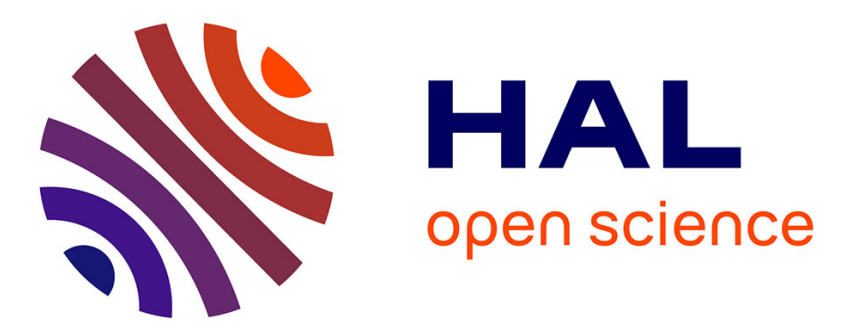

\title{
Synthesis of polyamide 6/nano-hydroxyapatite hybrid (PA6/n-HAp) for the sorption of rare earth elements and uranium
}

Taha Hassanein, Ahmed Masoud, Wael Mohamed, Mohamed Taha, Eric Guibal

\section{To cite this version:}

Taha Hassanein, Ahmed Masoud, Wael Mohamed, Mohamed Taha, Eric Guibal. Synthesis of polyamide 6/nano-hydroxyapatite hybrid (PA6/n-HAp) for the sorption of rare earth elements and uranium. Journal of Environmental Chemical Engineering, 2021, 9 (1), pp.104731. 10.1016/j.jece.2020.104731 . hal-03038621

\section{HAL Id: hal-03038621 \\ https://hal.mines-ales.fr/hal-03038621}

Submitted on 28 Jan 2021

HAL is a multi-disciplinary open access archive for the deposit and dissemination of scientific research documents, whether they are published or not. The documents may come from teaching and research institutions in France or abroad, or from public or private research centers.
L'archive ouverte pluridisciplinaire HAL, est destinée au dépôt et à la diffusion de documents scientifiques de niveau recherche, publiés ou non, émanant des établissements d'enseignement et de recherche français ou étrangers, des laboratoires publics ou privés. 


\title{
Synthesis of polyamide 6/nano-hydroxyapatite hybrid (PA6/n-HAp) for the sorption of rare earth elements and uranium
}

\author{
Taha F. Hassanein $^{\mathrm{a}, *}$, Ahmed M. Masoud ${ }^{\mathrm{b}, \mathrm{d}}$, Wael S. Mohamed ${ }^{\mathrm{c}}$, Mohamed H. Taha ${ }^{\mathrm{b}}$, \\ Eric Guibal ${ }^{\mathrm{d}}$ \\ ${ }^{a}$ Chemistry Department, Faculty of Science, Helwan University, 11795, Helwan, Cairo, Egypt \\ ${ }^{\mathrm{b}}$ Nuclear Materials Authority, P.O. Box 530, El Maddi, Cairo, Egypt \\ ${ }^{\mathrm{c}}$ Polymer \& Pigments Department, Chemical Industry Division, National Research Centre, 12622, Dokki, Giza, Egypt \\ ${ }^{\mathrm{d}}$ Polymer Composite and Hybrids, PCH, Institut Mines Telecom - Mines Ales, F-30319, Alès cedex, France
}

\begin{abstract}
A B S T R A C T
Polyamide (PA6) and hydroxyapatite (n-HAp) have intrinsic sorption properties for metal ions. Their association by melt compounding allows manufacturing a composite material (PA6/n-HAp) efficient for the binding of uranyl and rare earth metal ions (REEs) in acidic solution (in the pH range 2-2.5). The composite shows enhanced sorption capacities (5-7 times) compared with single PA6 material. The structuration of the material slightly improves textural properties but contributes to improve the accessibility and availability of reactive groups (including by size distribution). Metal sorption proceeds mainly through complexation of amide reactive groups as shown by FTIR characterization (modification of the environment of $\mathrm{C}=\mathrm{O}$ and $\mathrm{NH}$ groups) rather than ion-

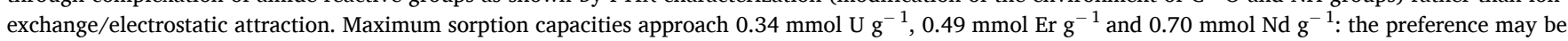
correlated to the covalent rather than ionic character of these metal ions. Uptake kinetics are relatively slow (requiring up to $6-8$ h, under selected experimental conditions): the textural properties of the composite (pore size: $2.6 \mathrm{~nm}$ ) limit the mass transfer properties (though slightly enhanced compared with PA6 precursor). The resistance to intraparticle diffusion constitutes the major con-trolling step for uptake kinetics. Nitric acid is the most efficient eluent for the desorption of loaded metals (ef-ficiency exceeds $94 \%$ ); noticeably U(VI) elution is optimal at $1 \mathrm{M}^{\mathrm{HNO}} \mathrm{H}_{3}$ concentration, contrary to REEs that require lower concentration (i.e., $0.1 \mathrm{M}$ ). Preliminary tests on sulfuric acid leachates of Egyptian ores demon-strate that the sorbent maintains good sorption properties for REEs and $U$ despite the complexity of the solution. The sorbent has a marked preference for REEs, $U$ and Th against base and alkali metals.
\end{abstract}

Keywords:

Polyamide

Nano hydroxyapatite

Composite sorbent

Uranyl and rare earth

Uptake kinetics

Sorption isotherms and desorption efficiency

Material characterization

\section{Introduction}

The removal of metal ions from contaminated water streams is an important challenge for industry because of the strengthening of governmental and international regulations, the demand of communities for better environmental protection, and the potential health effects associated with hazardous metal bioaccumulation. The recycling of valuable metals such as rare earth elements and the valorization of lowgrade resources (industrial wastes, sub-products, and marginal ores) are also of critical importance for the provisional supply of high-tech industries and nuclear power industry (uranium) [1,2]. Many resources simultaneously contain rare earths and uranium, especially in Egyptian mining areas. It is thus important designing processes that can contribute to the removal and valorization of these strategic metals from acid leachates. Indeed, leaching methods remain the most used techniques for the extraction (solid->liquid transfer) of metals from low-grade ores. In the liquid phase, the metals may be recovered by precipitation [3], mineral sorbents [4-8], agricultural wastes [9], functionalized composites [10,11], solvent extraction [1,12], activated carbon [13] or carbonized biomass [14], membrane processes [15], impregnated resin [16] or ion-exchange and chelating resins [17-22], depending on the composition of the leachates, the concentration of metals, and the flux of the effluent. Usually, sorption processes are preferred for the treatment of dilute solutions. Many reactive groups have shown affinity for rare earth and uranium including amidoxime [23-26], sulfonic and phosphonic groups [21,27-31].

\footnotetext{
* Corresponding author.

E-mail address: taha1m@yahoo.com (T.F. Hassanein).
} 
Polyamide-based materials [32-34] and soluble eggshell membrane protein-based nanocomposites adsorbents $[35,36]$ have been successfully tested for the recovery of metal ions, including uranium [15,37] and rare earths [38]. However, the sorption capacities were usually low (in the range $0.5-0.62 \mathrm{mmol} \mathrm{g}^{-1}$ for $\mathrm{Er}(\mathrm{III}), \mathrm{Tb}(\mathrm{III})$ and Dy(III)) with

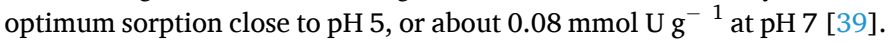
These materials have been also frequently designed as composite by incorporation of silica [40], clays [41,42], carbon [43] or biomass [44] to (a) improve specific surface area, (b) change hydrophilic/hydrophobic characteristics and (c) enhance sorption performance. The functionalization of polyamide-based materials has been also used for improving metal sorption [45-48].

Hydroxyapatite (HAp) is part of the mineral sorbents that were tested for metal sorption [39,49-54]. Porous hydroxyapatite binds up to 0.47 mmol $\mathrm{U} \mathrm{g}^{-1}$ [49]. For Nd(III) and Sm(III), sorption capacities as high as $2.24 \mathrm{mmol} \mathrm{Nd} \mathrm{g}^{-1}$ and $2.46 \mathrm{mmol} \mathrm{Sm} \mathrm{g}^{-1}$ were reported for nano-hydroxyapatite (n-HAp) [52]. Managing nanoparticles for the treatment of large water streams require complex solid/liquid separation; therefore, n-HAp is frequently associated to supports that improve the reactivity and the readily solid/liquid separation (surface deposition [55]; incorporation of magnetic particles [51,52], functionalization [56] etc.).

Composites associating polyamide and n-HAp have been previously designed for biological application [57-60]. These composite materials are usually manufactured by melt-compounding $[58,61]$. The literature on the application of this type of material for metal sorption is scarce. The objective of the current work precisely consists of evaluating the effect of the incorporation of n-HAp in polyamide 6 (PA6) on the sorption of $\mathrm{U}(\mathrm{VI}), \mathrm{Nd}(\mathrm{III})$ (as a representative of light rare earth elements, LREE) and Er(III) (heavy rare earth, HREE) from tri-component solutions. A special attention is paid to the recovery of these metals from acidic solutions because most of the leachates produced in the treatment of uranium ores are acidic. Therefore, the sorption performances for $\mathrm{U}$ (VI) and REE(III)s are compared for raw PA6 sorbent and PA6/n-HAp composite through (a) the study of the effect of $\mathrm{pH}$, sorbent dosage, and (b) the investigation of uptake kinetics, sorption isotherms, and metal desorption (selection of type and concentration of eluent). This comparison will help highlighting the beneficial effect of the incorporation of the mineral compound on the availability and accessibility of reactive groups (measured through the comparison of sorption isotherms and uptake kinetics) and the possible synergies of PA6 and $\mathrm{n}$-HAP. The physical and chemical properties are characterized through SEM, TEM (for n-HAp) observation, EDX, XRD, TGA, BET and FTIR spectroscopy analysis, and zetametry measurements, with the objective of identifying the sorption mechanisms involved in metal binding and the limiting steps in the transfer of target metals. The last part of the work consists of the use of the composite PA6/n-HAp sorbent for the treatment of an acidic leachate of local Egyptian ores (from El Sella mining area).

\section{Materials and methods}

\subsection{Materials}

Calcium nitrate tetrahydrate, $\mathrm{Ca}\left(\mathrm{NO}_{3}\right)_{2} \cdot 4 \mathrm{H}_{2} \mathrm{O}(99 \%)$ and ammonium hydroxide solution, $\mathrm{NH}_{4} \mathrm{OH}\left(25 \% \mathrm{NH}_{3}\right)$ were supplied by Sigma Aldrich Chemie $\mathrm{GmbH}$ (Taufkirchen, Germany). Ammonium phosphate trihydrate, $\left(\mathrm{NH}_{4}\right)_{3} \mathrm{PO}_{4} \cdot 3 \mathrm{H}_{2} \mathrm{O}(99 \%)$ was purchased from CHEMOS GmbH \& Co. KG (Altdorf, Germany). Polyamide 6 (PA6) powder was purchased from Sigma Aldrich Chemie GmbH (Taufkirchen, Germany).

Depleted uranyl nitrate solution $\left(10 \mathrm{~g} \mathrm{~L}^{-1}\right.$ stock solution, SPEX CertiPrep) was purchased from Fisher Scientific SAS (Illkirch-Graffenstaden, France). Erbium chloride $\left(\mathrm{ErCl}_{3}\right)$ and neodymium chloride $\left(\mathrm{NdCl}_{3}\right)$ were supplied by Sigma-Aldrich (Saint-Quentin-Fallavier, France). Nitric, hydrochloric, and sulfuric acids (analytical grade), used for desorption tests, were supplied by Sigma-Aldrich (Saint-Louis, MO,
USA).

\subsection{Synthesis of sorbent (PA6/n-HAp)}

\subsubsection{Synthesis of n-hydroxyapatite ( $n-H A p)$}

The wet method was used for preparing n-HAp nanoparticles. Calcium nitrate $(0.2 \mathrm{M}-50 \mathrm{~mL})$ was slowly dropped into the ammonium phosphate solution $(0.12 \mathrm{M}-50 \mathrm{~mL})$ under vigorous stirring $(900 \mathrm{rpm})$ at $80{ }^{\circ} \mathrm{C}$ for $4 \mathrm{~h}$ using a MS300 hot plate magnetic stirrer (Shanghai Leewen Scientific Instrument Co., Ltd, Shanghai, China). The $\mathrm{pH}$ was kept constant (in the range 10-12) using ammonium hydroxide solution $(25 \%, v / v)$. The synthesis procedure can be described by the equation:

$$
\begin{aligned}
& 10 \mathrm{Ca}\left(\mathrm{NO}_{3}\right)_{2}+6\left(\mathrm{NH}_{4}\right)_{3} \mathrm{PO}_{4}+2 \mathrm{NH}_{4} \mathrm{OH} \rightarrow \mathrm{Ca}_{10}\left(\mathrm{PO}_{4}\right)_{6}(\mathrm{OH})_{2} \\
& +20 \mathrm{NH}_{4} \mathrm{NO}_{3}
\end{aligned}
$$

The suspension was aged overnight at room temperature. The precipitate was collected by centrifugation, carefully washed through several rinsing steps using demineralized water. Finally, the material was dried at $80^{\circ} \mathrm{C}$ for $12 \mathrm{~h}$, before grinding to a powdered form.

\subsubsection{Synthesis of hybrid PA6/n-HAp}

The hybrid material was prepared by melt compounding [61-64], using a Haake twin-screw extruder (Haake, PolyLab QC, Thermo Scientific, Waltham, MA, USA). The hydroxyapatite was dried overnight (at $80{ }^{\circ} \mathrm{C}$ ) and stored in sealed desiccator prior to be incorporated into polyamide 6; it is important to remove any moisture from the mineral charge. Similarly, polyamide 6 chips were dried at $90{ }^{\circ} \mathrm{C}$ under vacuum for $24 \mathrm{~h}$ to remove adsorbed water. The melt-compounder (extruder) was operated at fixed rotational screw speed of $90 \mathrm{rpm}$, in the temperature range $250-255^{\circ} \mathrm{C}$. Under these conditions, the raw material can be melt and homogeneously mixed. Hydroxyapatite was incorporated at a mass dosage of $20 \% \mathrm{w} / \mathrm{w}$. The composite was extruded through a ribbon die into a cooling demineralized water bath and pelletized. The pellets were finally dried at $80^{\circ} \mathrm{C}$ under vacuum for $24 \mathrm{~h}$ and grinded to a powdered form. The material, after intermediary storage in desiccator, was kept into sealed bottles. Scheme 1 shows the tentative mechanism describing the interaction mode between n-HAp and PA6.

\subsection{Characterization of materials}

The textural properties were recorded on a Quantachrome BET surface analyzer (Nova 3200 Quantachrome Instruments, Boynton Beach, FL, USA), operated with NovaWin software (v. 11.03) for data treatment. The samples were initially out-gassed under vacuum $\left(10^{-4}\right.$ Torr $)$ at $150{ }^{\circ} \mathrm{C}$ for $3 \mathrm{~h}$. The BJH method was used for calculating the pore volume and pore size, while the specific surface area was deduced from multipoint BET method. The X-ray diffraction patterns were acquired using an Empyrean diffractometer (Malvern Panalytical, Malvern, UK) and the $\mathrm{Cu} \mathrm{K}_{\alpha}$ wavelength (i.e., $1.54060 \AA$ A; generator setup: $30 \mathrm{~mA} ; 45$ $\mathrm{kV}$ ). The morphology of nano-hydroxyapatite (n-HAp) was characterized by TEM analysis using a JEOL JEM-2100 electronic microscope (JEOL, Ltd., Tokyo, Japan) at an accelerating voltage of $120 \mathrm{kV}$. Fouriertransform infrared spectra were obtained using a Spectrum Two spectrometer (PerkinElmer, Waltham, MA, USA) equipped with an ATR sample base plate Diamond. Scanning electron microscopy was performed using a QUANTA FEG250 SEM (HV: $30 \mathrm{kV}$ ) (FEI Company, ThermoFisher Scientific, Waltham, MA, USA) equipped with a semiquantitative energy dispersive X-ray analyzer (integrated to QUANTA FEG250 SEM). The characterization of hybrid material was carried out on a DSM 962 SEM (Carl Zeiss Ltd., Cambridge, UK with an integrated EDX analyzer). Zetasizer analysis was performed using a Nano Series Zeta (Nano-ZS Malvern Instruments Ltd., Malvern, UK) for analysis of particle size and zeta potential. The pH-drift method [65] was used for quantifying the $\mathrm{pH}_{\mathrm{PZC}}$ of the materials. A fixed amount of sorbent (i.e., $100 \mathrm{mg}$ ) was distributed in a series of flasks $(25 \mathrm{~mL}$ aqueous solutions, 


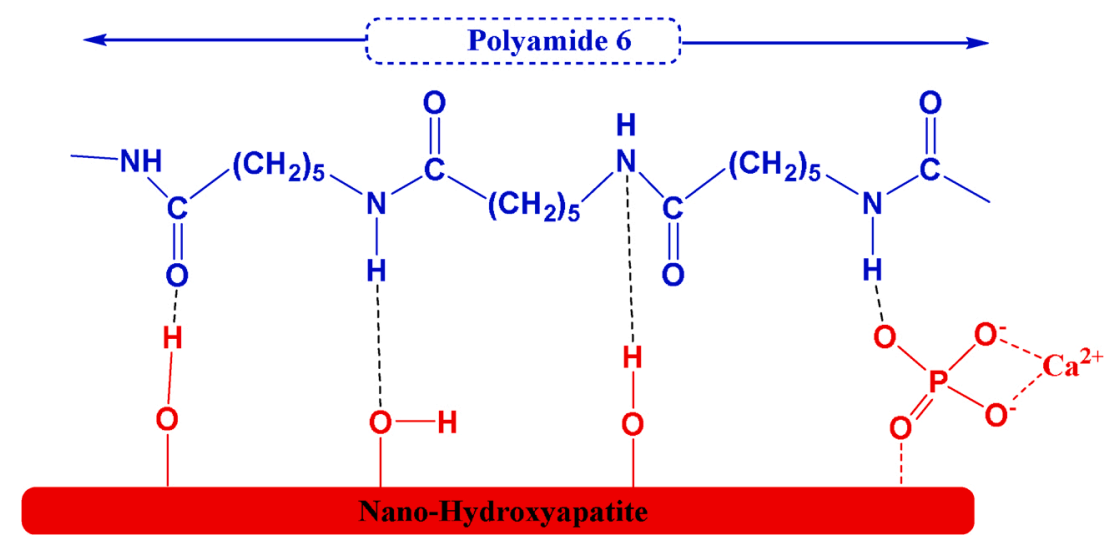

Scheme 1. Tentative mechanism for the linkage of n-HAp with PA6 (H-bonding).

containing $0.01 \mathrm{M} \mathrm{NaCl}$ as the background salt, and with different initial values of $\mathrm{pH}$, in the range 2-10). After $24 \mathrm{~h}$ of agitation, the final $\mathrm{pH}$ $\left(\mathrm{pH}_{\mathrm{eq}}\right)$ was measured and compared to initial $\mathrm{pH}$ value $\left(\mathrm{pH}_{0}\right)$. The $\mathrm{pH}_{\mathrm{PZC}}$ was approached by the $\mathrm{pH}$ value corresponding to $\mathrm{pH}_{0}=\mathrm{pH}_{\mathrm{eq}}$.

\subsection{Sorption studies}

\subsubsection{Synthetic solutions}

The sorption performances for $\mathrm{U}(\mathrm{VI})$ and REE(III)s from synthetic solutions are compared for raw PA6 sorbent and PA6/n-HAp composite. Sorption experiments were performed in batch mode. A fixed amount of sorbent $(\mathrm{m}, \mathrm{g})$ was mixed with a fixed volume $(\mathrm{V}, \mathrm{L})$ of metal-containing solution for a fixed contact time (i.e., $24 \mathrm{~h}$ ) at room temperature (i.e., 25 $\pm 2{ }^{\circ} \mathrm{C}$ ). The $\mathrm{pH}$ was not controlled during sorption experiments; however, the final $\mathrm{pH}$ value was systematically recorded using a Cyber Scan pH 6000 pH-meter (Eutech Instruments, Nijkerk, Netherlands). After contact, the solutions were separated and the residual metal concentration $\left(\mathrm{C}_{\mathrm{eq}}, \mathrm{mmol} \mathrm{L}^{-1}\right)$ was evaluated by ICP-AES (inductively-coupled plasma atomic emission spectrometer, Activa M, Horiba-Jobin Yvon, Longjumeau, France). The sorption experiments were duplicated and the average value is calculated and used for sorption quantification; deviation did not exceed 5\%. Annex A shows some example of the good reproducibility in sorption performances (for the study of the effect of sorbent dosage and uptake kinetics, Figs. A1 and A2, respectively).

For the study of $\mathrm{pH}$ effect (mono-component solutions), the initial metal concentration $\left(\mathrm{C}_{0}, \mathrm{mg} \mathrm{L}^{-1}\right.$ or $\left.\mathrm{mmol} \mathrm{L}^{-1}\right)$ was set to $\sim 50 \mathrm{mg} \mathrm{L}^{-1}$ $\left(0.2 \mathrm{mmol} \mathrm{U} \mathrm{L}^{-1}, 0.36 \mathrm{mmol} \mathrm{Nd} \mathrm{L}^{-1}\right.$ or $\left.0.30 \mathrm{mmol} \mathrm{Er} \mathrm{L}^{-1}\right)$; the sorbent dosage (SD) was $1 \mathrm{~g} \mathrm{~L}^{-1}$. For the other studies, the initial $\mathrm{pH}$ was set to $2.04 \pm 0.3$ and experiments were performed in multi-component solutions $\left(\mathrm{C}_{0}: 50 \mathrm{mg} \mathrm{L}^{-1}\right.$ of each metal ions). While investigating the effect of sorbent dosage, $\mathrm{SD}$ was varied between 0.25 and $2 \mathrm{~g} \mathrm{~L}^{-1}$. For the study of sorption isotherms, the concentration of metal ions, $\mathrm{C}_{0}$, was varied between 30 and $300 \mathrm{mg} \mathrm{L}^{-1}$ of each metal ions. The residual concentrations were used for the determination of the sorption capacity ( $\mathrm{q}_{\mathrm{eq}}$, mmol $\left.\mathrm{g}^{-1}\right)$ using the mass-balance equation: $\mathrm{q}_{\mathrm{eq}}=\left(\mathrm{C}_{0}-\mathrm{C}_{\mathrm{eq}}\right) \times \mathrm{V} / \mathrm{m}$, and the sorption efficiency (\%). Metal desorption was also carried out in batch systems using roughly the same experimental conditions (i.e., SD: $1 \mathrm{~g} \mathrm{~L}^{-1}$; room temperature; contact time: $24 \mathrm{~h}$ ) by contact of the metalloaded sorbent with a fixed volume of eluent (nitric acid, hydrochloric acid or sulfuric acid) at three levels of concentrations $(0.1 \mathrm{M}, 0.5 \mathrm{M}$ and $1 \mathrm{M})$. After completion, the residual concentration in the filtrate was analyzed for evaluating the desorption efficiency.

The recycling of the sorbent (testing of sorption and desorption efficiencies) for 5 successive cycles was investigated by loading PA6/nHAp with a ternary metal solution (at pH 2.03, containing $50 \mathrm{mg} \mathrm{L}^{-1}$ of U(VI), Nd(III) and $\operatorname{Er}(\mathrm{III})$ ). The sorbent dosage was set to $1 \mathrm{~g} \mathrm{~L}^{-1}$ and the contact time was $24 \mathrm{~h}$. The desorption of metal ions was carried out using again a sorbent dosage of $1 \mathrm{~g} \mathrm{~L}^{-1}$ while the eluent was nitric acid; the suspension was maintained under agitation for $24 \mathrm{~h}$. Desorption steps were processed sequentially beginning with $0.1 \mathrm{M} \mathrm{HNO}_{3}$ solutions for the elution of REEs, followed by $1 \mathrm{M} \mathrm{HNO}_{3}$ solutions for the recovery of $\mathrm{U}(\mathrm{VI})$. The solutions were mixed and analyzed for determining the cumulative desorption of target metals.

Table S1 (see Supplementary Information) reports the conventional equations used for modelling sorption isotherms and uptake kinetics. The parameters of these models were obtained by non-linear fitting with the facilities of Mathematica ${ }^{\circledR}$ software. The quality and the comparison of the fits were analyzed by both the determination coefficients $\left(R^{2}\right.$, comparing calculated and experimental data) and the AIC (Akaike Information Criterion).

\subsubsection{Tests on ore leachate}

In order to evaluate the robustness of sorption properties in complex solutions, a geological sample collected in an Egyptian mining site (El Sella area, Southeastern desert, [66]) was submitted to a sulfuric acid leaching. Grinded uranium ore (particle size $\sim 74 \mu \mathrm{m}$ ) was mixed with a $10 \%(\mathrm{w} / \mathrm{w})$ sulfuric acid solution for $4 \mathrm{~h}$ at $45^{\circ} \mathrm{C}$ : the solid/liquid mass ratio was 1:2 [67]. Filtrated leachate, after adjusting the $\mathrm{pH}$ to 1.96 using $\mathrm{NaOH}$, was used for testing the recovery of a series of metal ions by PA6/n-HAp. The sorbent dosage was set to $1 \mathrm{~g} \mathrm{~L}^{-1}$; the sorption experiment was carried out at room temperature for a contact time of 8 h. Global index for REEs was determined using the Arsenazo III spectrophotometric method [68]. The concentration of $\mathrm{P}_{2} \mathrm{O}_{5}$ was determined by the ammonium molybdate and ammonium metavanadate method [69]. The concentrations of other metal ions were determined by ICP-AES. Sulfate concentration was obtained according to APHA Method (4500-SO $\mathrm{SO}_{4}^{2-}$ ) of the standard methods for the examination of water and wastewater [70].

\section{Results and discussion}

\subsection{Characterization of $n-H A p$ and $P A 6 / n-H A p$}

\subsubsection{Morphology and chemical composition - TEM, SEM and SEM-EDX analysis}

Fig. S1 (see Supplementary Information) shows the TEM characterization of n-HAp particles. Though some aggregates can be identified, most of the particles can be classified in two groups: $6-16 \mathrm{~nm}$ and $30-40 \mathrm{~nm}$. In any cases, most of these particles can be qualified as nanoparticles. The process selected for the synthesis of hydroxyapatite allows manufacturing nanoparticles and the mineral fraction will be called n-HAp. Fig. 1 shows SEM microphotographs at different magnitudes to illustrate the heterogeneity in size and shape of the different objects. The melt compounding produces a material containing a homogeneous continuous phase (PA6 and n-HAp matric) embedding irregular larger objects that consist of PA6. Fig. S2 shows the SEM 


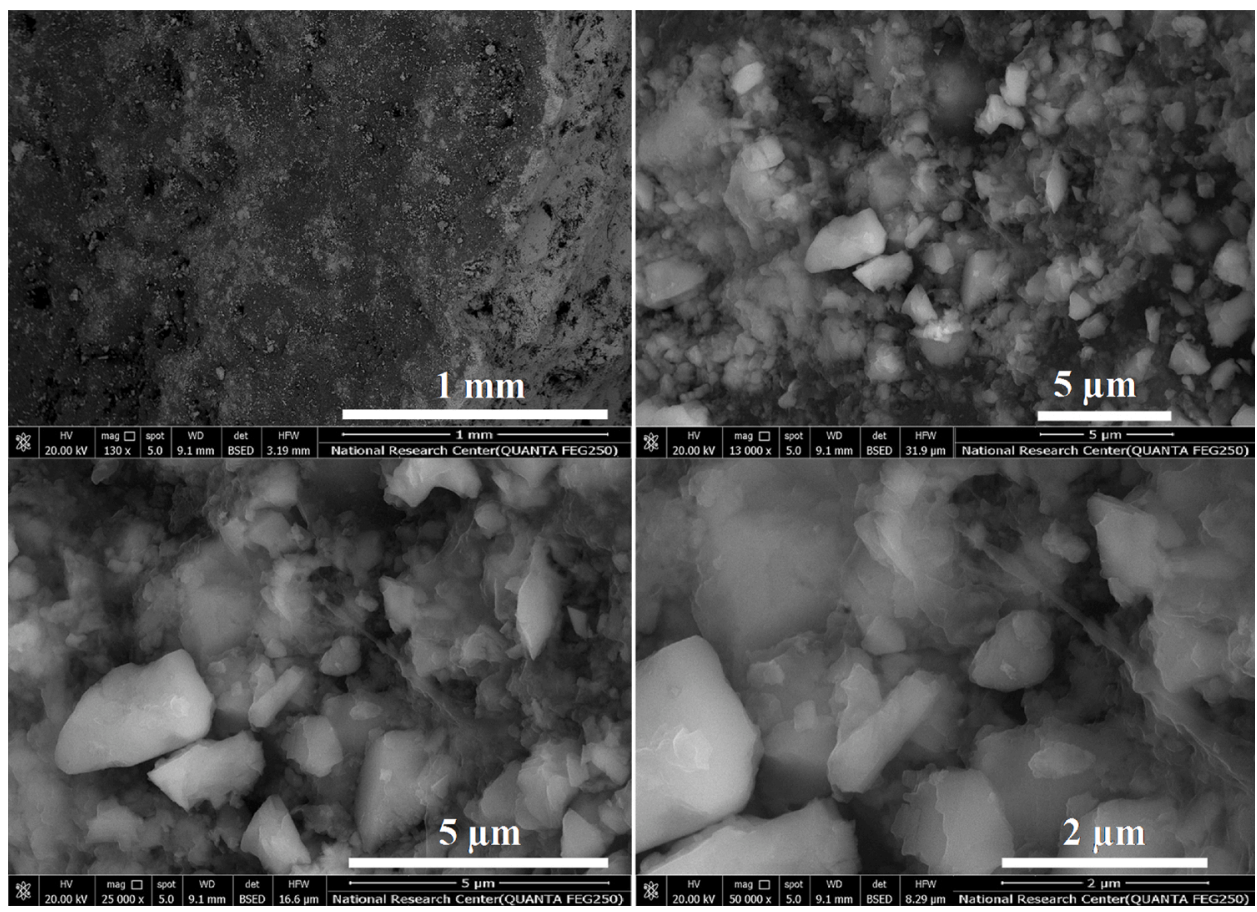

Fig. 1. SEM photomicrographs of PA6/n-HAp sorbent at different magnitudes.

observation of PA6, n-HAP and composite PA6/n-HAp together with their semi-quantitative EDX analysis. The stoichiometric ratios $\mathrm{C} / \mathrm{O}$ and $\mathrm{C} / \mathrm{N}$ are supposed to be close to 6 in PA6; here, the ratios are lower (in the range 4.41-4.68). The N/O ratio is close to 1 (consistently with PA6 formula). For n-HAp the porous structure is clearly appearing on the SEM microphotograph; the surface aspect is consistent with the pictures reported by Yan et al. [71]. Xia et al. [72] reported different structures associated with nanosheet formation in the synthesis of n-hydroxyapatite depending on the synthesis procedure. The semi-quantitative analysis shows that the $\mathrm{O} / \mathrm{P}$ and $\mathrm{O} / \mathrm{Ca}$ ratios are much lower (i.e., 2.07 and 1.59, respectively) than expected from theoretical formula $\mathrm{Ca}_{5}\left(\mathrm{PO}_{4}\right)_{3}(\mathrm{OH})$ (i.e., 4.33 and 2.60 , respectively). The $\mathrm{Ca} / \mathrm{P}$ atomic ratio is close to 1.29; much lower than theoretical 1.67 ratio; $\mathrm{Ni}$ and Fox [73] reported even higher $\mathrm{Ca} / \mathrm{P}$ atomic ratio (close to 2.1 ). This probably means that the synthesis does not produce pure hydroxyapatite and that several compounds based on calcium phosphate may coexist; this is consistent with further XRD characterizations (see below). In the case of the composite, the embedment of n-HAp in PA6 results in more compact surface (compared with n-HAp) with many micro particles deposited on the surface. The semi-quantitative analysis shows that the $\mathrm{C} / \mathrm{N}$ atomic ratio (which can be considered a marker of PA6 compound) is close to 3.06, much lower than for raw PA6 (i.e., 4.68). While for raw n-HAp the $\mathrm{Ca} / \mathrm{P}$ ratio was close to 1.29 , in the composite the ratio increases to 2.84 . This means that unexpectedly the melt compounding substantially modifies the chemical composition of the products incorporated in the composite. The relative fractions of $\mathrm{P}$ and $\mathrm{Ca}$ (markers of $\mathrm{n}-\mathrm{HAp}$ ) in the composite are about 8.13 to 3.69 lower than their atomic fractions in raw n-HAp. Based on these relative decreases the n-HAp content in the composite, hydroxyapatite represents between 12 and $27 \%$ of PA6/n-HAp. This order of magnitude is consistent with the relative weight fractions of PA6 and n-HAp in the synthesis procedure (i.e., 80:20) and with the weight loss at $600{ }^{\circ} \mathrm{C}$. Exposed overnight at a temperature of $600{ }^{\circ} \mathrm{C}$ in a vacuum muffle furnace, the weight loss (due to thermal degradation of PA6) represented $20.9 \%$.

\subsubsection{Textural properties - BET analysis}

Figs. S3 and S4 show the overview of the textural analysis of n-HAp, PA6 and PA6/n-HAp materials including BET surface area $\left(\mathrm{S}_{\mathrm{BET}}\right)$ and pore size distribution. The $\mathrm{N}_{2}$ sorption-desorption curves are typical of Type II(b) sorption isotherm with a limited hysteresis phenomenon. For $\mathrm{n}$-HAp, the $\mathrm{S}_{\mathrm{BET}}$ is evaluated close to $61.6 \mathrm{~m}^{2} \mathrm{~g}^{-1}$. This is consistent with the values reported by Yan et al. [71] for the synthesis of hydroxyapatite using distiller wastes, but much lower from the values cited by Xia et al. [72] in the case of hydroxyapatite produced from perforated shell powder (i.e., $188 \mathrm{~m}^{2} \mathrm{~g}^{-1}$ ). Xia et al. characterized the effect of experimental procedures on the average pore size of different n-HAp materials from 6 to $69 \mathrm{~nm}$; the present material shows an intermediary value for pore size (i.e., $36.4 \mathrm{~nm}$ ). Similar trends were recorded for PA6/montmorillonite materials [42]. The pore volume of $n$-HAp being close to $0.33 \mathrm{~cm}^{3} \mathrm{~g}^{-1}$ is much lower than the value reported by Xia et al. for their specific productions $\left(\sim 1.31 \mathrm{~cm}^{3} \mathrm{~g}^{-1}\right)$ but in the middle range of commercial n-HAp substrates $\left(0.15-0.96 \mathrm{~cm}^{3} \mathrm{~g}^{-1}\right)$ [72]. The PA6 material also presents a Type II(b) sorption isotherm with little hysteresis; the specific surface area is found close to $13.2 \mathrm{~m}^{2} \mathrm{~g}^{-1}$; this value is consistent with the $S_{\text {BET }}$ of PA6 nanofiber membranes (close to $15.8 \mathrm{~m}^{2} \mathrm{~g}^{-1}$ ) [74]. The pore volume and the average pore size are close to $0.086 \mathrm{~cm}^{3} \mathrm{~g}^{-1}$ and $2.2 \mathrm{~nm}$, respectively; the material can be considered microporous; hindering the diffusion of metal ions into the sorbent. The incorporation of n-HAp has a limited impact on the textural properties of the composite: the $S_{\mathrm{BET}}$ is hardly increased to $14.7 \mathrm{~m}^{2} \mathrm{~g}^{-1}$, the pore volume to $0.105 \mathrm{~cm}^{3} \mathrm{~g}^{-1}$, and the average pore size to $1.6 \mathrm{~nm}$. The coating of n-HAp porosity with PA6 during the melt compounding drastically reduces the textural properties of the mineral support.

\subsubsection{Crystallographic properties - XRD analysis}

The XRD diffraction patterns for the three materials are reported in Fig. S5. The patterns are weakly resolved with the presence of many peaks. The most representative are reported on the Table associated to Fig. S5. In the case of $\mathrm{n}-\mathrm{HAp}$, the main peaks (at $2 \theta: 6.60^{\circ}, 8.3^{\circ}$ and $\left.15.92^{\circ}\right)$ are associated with the crystal planes (100), (-110) and (-111) of octacalcium phosphate (reported to $4.7^{\circ}, 9.0^{\circ}$ and $15.8^{\circ}$ by Xia et al. [72]). However, some peaks surrounding the characteristic peaks apparently indicate the presence of other phases such as calcium hydrophosphate $\left(2 \theta: 11.6^{\circ}\right.$ and $23.4^{\circ}$, [72]) for example. Usually, PA6 XRD patterns are poorly resolved and characterized by two main peaks identified at $2 \theta: 20.4^{\circ}$ and $24.1^{\circ}$ [75]; here, the two main peaks are 
detected at $2 \theta: 18.33^{\circ}$ and $20.70^{\circ}$. They are surrounded by a series of peaks that make difficult the identification of crystal planes. As expected, PA6 is much less crystalline than n-HAp. The melt compounding of PA6 and n-HAp leads to XRD patterns that logically combine the contributions of the two compounds. As reported by Mehrabian and Nasr-Esfahani [75], the XRD pattern of the composite shows the superposition of the two patterns; slight shifts in the $2 \theta$ positions are observed (see Table in Fig. S5); this is probably due to the intercalation of PA6 in the planes of n-HAp.

\subsubsection{Functionalization - FTIR analysis}

The investigation of composites based on PA6 (produced by melt compounding of the polymer with fillers, charges and other polymers) provides a basis for the interpretation of the interactions between PA6 and n-HAp. Different mechanisms have been reported for explaining, for example, the interactions between hydroxyapatite, polyamide and polyethylene [64], including H-bonding (see Scheme 1). This mechanism was previously documented [58,76-79].

Fig. 2 reports the FTIR spectra of PA6, n-HAp, composite sorbent before and after the sorption of metal ions. The figure is focused on the $2000-450 \mathrm{~cm}^{-1}$ wavenumber range because in the region $4000-200$ $\mathrm{cm}^{-1}$ the differences are not marked enough to bring meaningful information. Table S2 reports the assignments of the main peaks for the different materials (and relevant references). Some peaks representative of phosphate groups $(\mathrm{P}=\mathrm{O}$ stretching, $\mathrm{P}-\mathrm{O}$ stretching) stretching are identified around $1090 \mathrm{~cm}^{-1}, 1026 \mathrm{~cm}^{-1}, 963 \mathrm{~cm}^{-1}, 601 \mathrm{~cm}^{-1}, 562$ $\mathrm{cm}^{-1}$ and $471 \mathrm{~cm}^{-1}$ on n-HAp spectrum. Some of these peaks disappear ( $\mathrm{P}-\mathrm{O}$ stretching $\left(\nu_{3} \mathrm{PO}_{4}\right.$ stretching $)$ at $1025.77 \mathrm{~cm}^{-1}, \nu_{1} \mathrm{PO}_{4}$ stretching at $962.61 \mathrm{~cm}^{-1}$, and P-O stretching/ $\nu_{4} \mathrm{PO}_{4}$ stretching or phosphate bending at $600.80 \mathrm{~cm}^{-1}$ ) or are strongly shifted after incorporation with $\mathrm{PA6}$ (to form $\mathrm{PA6} / \mathrm{n}$-HAp); for example $\mathrm{P}=\mathrm{O}$ stretching vibration shifted from $1089.63 \mathrm{~cm}^{-1}$ to $1064.74 \mathrm{~cm}^{-1}$. It is noteworthy that FTIR spectrum tends to indicate that carbonate may be present on the material as shown by the presence of $\mathrm{CO}_{3}$ stretching signal (at $1419.65 \mathrm{~cm}^{-1}$ ).

PA6 shows typical bands of amide groups, including $\mathrm{C}-\mathrm{O}, \mathrm{C}-\mathrm{N}$ and $\mathrm{C}=\mathrm{O}$ vibrations, at $1636.94 \mathrm{~cm}^{-1}$ (C-O and C-N stretching), 1535.00 $\mathrm{cm}^{-1}$ (C-N stretching or C-N bending), $1263.03 \mathrm{~cm}^{-1}$ (C-N stretching and /or $\mathrm{C}=\mathrm{O}$ bending), $686.73 \mathrm{~cm}^{-1}$ (Amide V, band). After melt compounding, the sorbent shows the combination of PA6 and n-HAp spectra with some weak shifts of characteristic wavenumbers (see Table S2). It is noteworthy that some peaks disappear; for example at $628.8 \mathrm{~cm}^{-1}$ and $600.8 \mathrm{~cm}^{-1}$ (corresponding to $\delta \mathrm{OH}$ deformation and
$\mathrm{P}-\mathrm{O}$ stretching/or phosphate bending vibrations, respectively): the interaction of PA6 with n-HAp affects the vibrational environment of these reactive groups. New peaks appear at $\sim 893.7 \mathrm{~cm}^{-1}$ and $\sim$ $801-173 \mathrm{~cm}^{-1}$ (probably associated to carbonate vibrations), $\sim 522.8$ $\mathrm{cm}^{-1}$ (not assigned or resulting from the shift (or the splitting) of the $\mathrm{PO}_{4}$ stretching vibration initially detected at $561.7 \mathrm{~cm}^{-1}$. A shoulder appears around $1597 \mathrm{~cm}^{-1}$; this means that the environment of amide groups is affected by the interaction with hydroxyapatite. In addition, two strong peaks also appears at $\sim 1135.8 \mathrm{~cm}^{-1}$ and $\sim 1738 \mathrm{~cm}^{-1}$. The peak at $1738 \mathrm{~cm}^{-1}$ is generally associated with carboxyl groups; this may be explained by the linkage between hydroxyl group of hydroxyapatite and the carbonyl group of amide site of PA6 [64]. These observations confirm that different modes of interaction may contribute to the synthesis of the composite. Zuo et al. [64] identified hydrogen bonding and interactions between hydroxyl and phosphate from n-HAp and carboxyl and amine groups of PA6. Zhang et al. [76] reported the formation of hydrogen bonds between the amide group of PA66 and hydroxyl groups of hydroxyapatite in the synthesis of n-HA/PA66 composite.

The figure also reports the FTIR spectrum of PA6/n-HAp after metal sorption. Substantial changes are observed: the peaks at $1136 \mathrm{~cm}^{-1}$, $1065 \mathrm{~cm}^{-1}, 999 \mathrm{~cm}^{-1}, 894 \mathrm{~cm}^{-1}$ and $783 \mathrm{~cm}^{-1}$ disappear. In addition, the weak shoulder appeared around $1600 \mathrm{~cm}^{-1}$ is weakened. These peaks were associated to the interactions between PA6 and n-HAp. This means that the amide groups $(-\mathrm{NH}, \mathrm{C}=\mathrm{O}$ ) are the most reactive among the phosphate, carboxyl and amine groups present on the composite. It is noteworthy that the FTIR spectra of PA6 and PA6/n-HAp after metal sorption are very close; the main difference is observed at $1738 \mathrm{~cm}^{-1}$ (which is not reversed by metal binding). In addition, the peaks appearing at $1233 \mathrm{~cm}^{-1}$ and $1217 \mathrm{~cm}^{-1}$ (which are not present on both PA6 and PA6/n-HAp FTIR spectra) are representative of the specific interaction between metal ions and reactive groups at the surface of the composite material. The neighboring peak at $1263 \mathrm{~cm}^{-1}$ is assigned to amide groups; this could support the shift of the signal of a fraction of these reactive groups with metal binding.

\subsubsection{Particle size and surface charge - Zetametry}

Zetametric measurements allow characterizing both the size of the particles that were used for sorption tests (see Fig. S6) and the characterization of their zeta potential in water. Polyamide has a little higher negative charge than other materials. Dietz et al. [37] reported positive zeta potential for polyamide at $\mathrm{pH} 3$, while the charge changes to negative at $\mathrm{pH} 4.5$ and above. Janusz and Skwarek [80] characterized

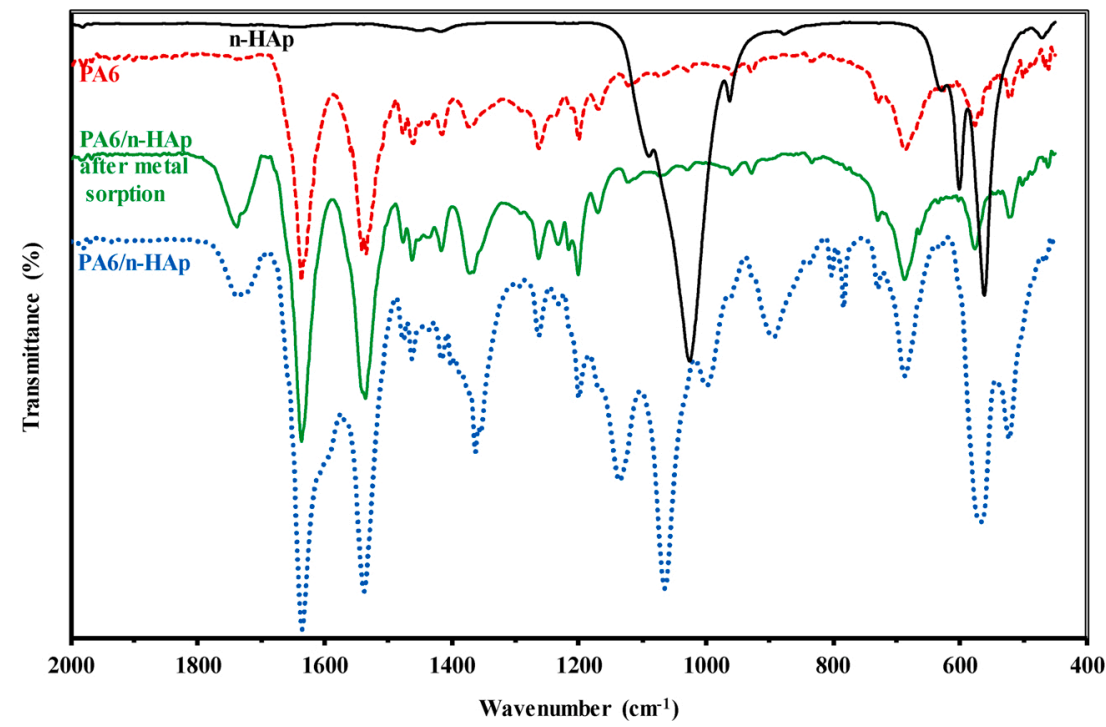

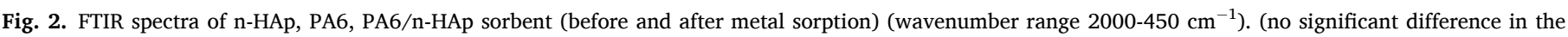
range $4000-2000 \mathrm{~cm}^{-1}$, except the absence of signals for mineral substrate, n-HAp). 
hydroxyapatite with $\mathrm{pH}$ PZC close to 7.5 while the $\mathrm{pH}_{\text {IEP }}$ was below $4 . \mathrm{Ni}$ and Fox [73] report a $\mathrm{pH}$ PzC $\sim 6.0-7.0$ for hydroxyapatite. The melt compounding does not change significantly the overall negative charge of the composite: the net charge in demineralized water is closed to - 15 $\mathrm{mV}$, intermediary between those of $\mathrm{n}$-HAp (i.e., $-12 \mathrm{mV}$ ) and PA6 (i.e., $-25 \mathrm{mV}$ )

The analysis particle size of the three materials confirm that hydroxyapatite can be considered of nanometer-size $(\sim 54 \mathrm{~nm})$, as well as the composite $(\sim 67 \mathrm{~nm})$. On the opposite hand, PA6 raw material exhibit much larger particles, close to $602 \mathrm{~nm}$. Obviously, the difference in size will induce a strong impact on mass transfer properties and uptake kinetics.

Debye-Scherrer equation was used to calculate the average crystallite size (L) ofn-HAp, PA6 and PA6/n-HAp (Table S3) depending on XRD data (Fig. S5) [36]. The crystallite sizes obtained from Scherrer equation were less than those obtained from TEM and Zetasizer measurements.

The size obtained from Scherrer's formula is not necessarily the same as the particle size. This is the case for partly crystalline powders and aggregated powders made up of smaller primary particles [81]. Furthermore, powders are normally not monodisperse but consist of a size distribution. The polydispersity of nanopowders is not taken into account in Scherrer's formula [81].

Comparatively, particle size calculated from TEM and Zetasizer measurements will be more reliable. It seems that calculated crystallite size using Scherrer equation is less than the real size [82]. The point to be noted for the three materials is that a particle is composed of more individual crystallites. For example, crystallite size with $6.13 \mathrm{~nm}$ (determined from Scherrer equation) for n-HAp, and particle size $30-40 \mathrm{~nm}$ (from TEM) means that crystallite size $<$ particle size and confirms that each particle is composed of many crystallites.

Fig. S7 shows the comparison of $\mathrm{pH}_{\mathrm{PZC}}$ values for PA6 (i.e., 6.97) and PA6/-nHAp (i.e., 7.62) deduced from pH-drift titration. Apparently, these $\mathrm{pH}_{\mathrm{PZC}}$ values are close to those of hydroxyapatite (see above; i.e., 6-7 to 7.5 depending on the synthesis routes). Consistently with the comparison of the zeta potential of the materials in suspension into water, the melt compounding hardly changes the range of $\mathrm{pH}_{\mathrm{PZC}}$ values obtained with the pH-drift method (while comparing n-HAp, PA6 and the composite). Both PA6 and PA6/n-HAp materials are positively charged in acidic solutions. When the $\mathrm{pH}$ increases, the charge repulsion of metal cations with protonated surface groups progressively decreases. It is thus possible anticipating that with the increase of the $\mathrm{pH}$ the sorbents have a surface charge more compatible for the binding of metal cations.

\subsection{Sorption properties}

\subsection{1. $p H$ effect - Charge and functional affinity for metal binding}

The effect of the $\mathrm{pH}$ is an important parameter in the design and optimization of a sorption process. In the case of metal ions, the $\mathrm{pH}$ influences not only the surface charge of the sorbent and its potential effect of attraction or repulsion of solute molecules, but also the speciation of the metal ions. Under the experimental conditions selected for this study, the speciation of rare earths is remains almost constant between $\mathrm{pH} 1$ and $\mathrm{pH}$ 6: free REEs(III) represent the predominant species: $\mathrm{Nd}(\mathrm{III})$ fraction is higher than $99.4 \%$. In the case of $\mathrm{Er}(\mathrm{III})$ the fraction of free $\mathrm{Er}(\mathrm{III})$ decreases down to $97.7 \%$ with increasing the $\mathrm{pH}$ up to $\mathrm{pH} 6$ (free $\mathrm{Er}(\mathrm{III})$ is about $99.8 \%$ at $\mathrm{pH}$ 5), while Er(III) also appears as $\mathrm{ErOH}^{2+}$ traces. On the opposite hand, the aqueous chemistry of $\mathrm{U}(\mathrm{VI})$ is strongly changed by the $\mathrm{pH}$ (Fig. S8, using Visual MINTEQ, [83]). At pH $1, \mathrm{U}(\mathrm{VI})$ is present as free uranyl (about $93.71 \%$, completed with $\mathrm{UO}_{2} \mathrm{Cl}^{+}$). At pH 3, the metal is only present under its free cation form (i. e., $\mathrm{UO}_{2}^{2+}$ ). Above $\mathrm{pH} 3$, the speciation diagram shows the increasing formation of hydrolyzed species, including $\mathrm{UO}_{2} \mathrm{OH}^{+}$and polynuclear species (i.e., $\left(\mathrm{UO}_{2}\right)_{2}(\mathrm{OH})_{2}^{2+},\left(\mathrm{UO}_{2}\right)_{3}(\mathrm{OH})_{4}^{+},\left(\mathrm{UO}_{2}\right)_{4}(\mathrm{OH})_{7}^{+}$, none of them exceeding $16 \%$ and the most significant species: $\left.\left(\mathrm{UO}_{2}\right)_{3}(\mathrm{OH})_{5}^{+}\right)$represents up to $57.2 \%$ at $\mathrm{pH}$ 5.02. It is noteworthy that above $\mathrm{pH} 5.03$, the software predicts the possible formation of insoluble uranium species. The zetametry characterization showed that in demineralized water the surface charge of the different sorbents is globally negative (in the range $-25 /-12 \mathrm{mV}$ ). This means that the sorbent can bind positive species by electrostatic attraction at $\mathrm{pH}$ close to neutrality. In acidic conditions, the surface charge becomes positive (see the results of the $\mathrm{pH}$-drift method).

Fig. 3 shows that for PA6, the sorption of REEs increases with the $\mathrm{pH}$ from $0.02 \mathrm{mmol} \mathrm{g}^{-1}$ to $0.07-0.08 \mathrm{mmol} \mathrm{g}^{-1}$, the sorption of $\mathrm{Nd}(\mathrm{III})$ being slightly higher than that of $\operatorname{Er}(\mathrm{III})$. The progressive deprotonation of sorbent surface favors the binding of metal cations. Rho et al. [84] reported a $\mathrm{pH}_{\mathrm{PZC}}$ value close to 6.3 for polyamide nanofiltration membranes. This would suggest that the support remains positively charged on the whole range of $\mathrm{pH}$ tested for metal sorption; however, the overall charge progressively decreases making more favorable the sorption of $\mathrm{Nd}(\mathrm{III})$ and $\mathrm{Er}(\mathrm{III})$. The positive charge of both the sorbent and the metal ions means that their sorption proceeds through chelation on amide reactive groups (carbonyl and/or amine sites) rather than electrostatic attraction. In the case of uranyl sorption, the levels of uptake are very

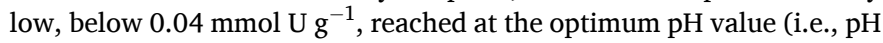
$3)$. Between $\mathrm{pH} 1$ and 3 the progressive deprotonation reduces the charge repulsion of free uranyl species by charged PA6 surface. Above $\mathrm{pH} 3$, despite a less defavorable surface charge the sorption tends to decrease; this is probably due to the progressive decrease in the relative fraction of free uranyl (Fig. S8) and the formation of hydrolyzed and polynuclear species of larger ionic size (which may limit the accessibility to internal sites). In the case of composite sorbent, the sorption properties are considerable increased. Under comparable experimental conditions, the sorption capacities for $\mathrm{Nd}$ (III) vary between 0.3 and 0.35 mmol $\mathrm{Nd} \mathrm{g}^{-1}$, with limited effect of $\mathrm{pH}$ (slightly higher around $\mathrm{pH}_{\mathrm{eq}} 3$ ) while for $\mathrm{Er}(\mathrm{III})$ the sorption capacity increases from $0.24 \mathrm{mmol} \mathrm{Er} \mathrm{g}^{-1}$ at $\mathrm{pH} 1$ to $0.27-0.28 \mathrm{mmol} \mathrm{Er}^{-1}$ in the range $\mathrm{pH}_{\mathrm{eq}}: 2-6$. The $\mathrm{pH}$ has globally a limited effect on REE binding; the sorption being slightly higher around $\mathrm{pH}$ 3. For uranyl, the $\mathrm{q}=\mathrm{f}(\mathrm{pH})$ profile is similar to the profile observed for PA6. It is noteworthy that in acidic region, the sorption capacity slightly increases from $\mathrm{pH}_{\mathrm{eq}} 1$ to $\mathrm{pH}_{\mathrm{eq}} 3$ (from 0.14 to $0.17 \mathrm{mmol} \mathrm{U} \mathrm{g}^{-1}$ ) before strongly decreasing above $\mathrm{pH} 3$ down to 0.3 $\mathrm{mmol} \mathrm{U} \mathrm{g}^{-1}$. The composite shows sorption capacities 3-4 times higher than PA6 precursor.

For REE cations, the decrease in the overall surface charge of the sorbents favors their sorption by the reduction of repulsion effect and probably by chelation on $-\mathrm{NH}$ and carbonyl/carboxyl groups (two reactive groups that have been affected by metal binding on FTIR spectra). For uranyl species, the sorption is also slightly increased with

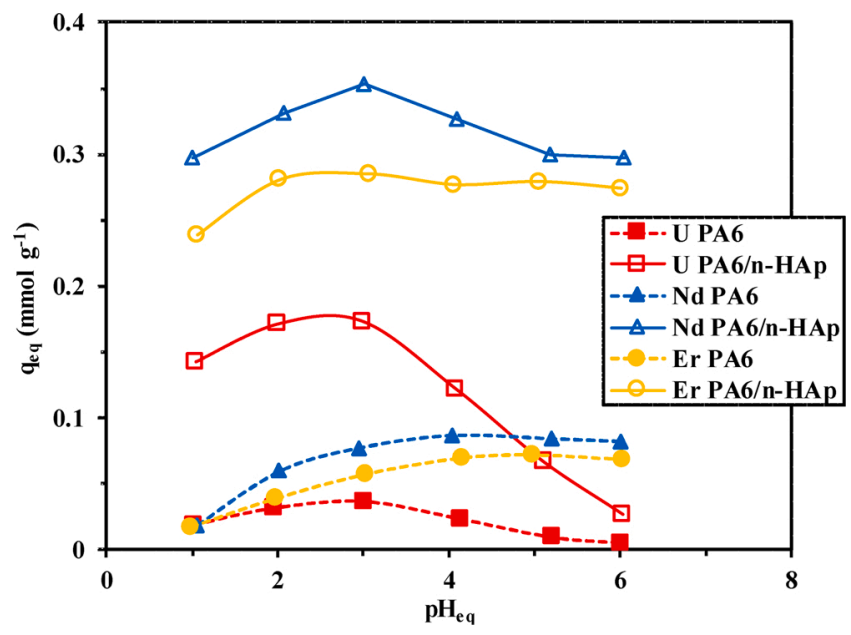

Fig. 3. Effect of equilibrium $\mathrm{pH}$ on the sorption of U(VI), $\mathrm{Nd}(\mathrm{III})$ and $\mathrm{Er}(\mathrm{III})$ using PA6 and PA6/n-HAp (mono-component solutions; Sorbent dosage, SD: $1 \mathrm{~g}$ $\mathrm{L}^{-1} ; \mathrm{C}_{0}: 50 \mathrm{mg} \mathrm{L}^{-1}, 0.205 \mathrm{mmol} \mathrm{U} \mathrm{L}^{-1}, 0.344 \mathrm{mmol} \mathrm{Nd} \mathrm{L}^{-1}$ or $0.298 \mathrm{mmol} \mathrm{Er}$ $\mathrm{L}^{-1}$; room temperature; contact time: $24 \mathrm{~h}$ ). 
$\mathrm{pH}$ augmentation, until reaching $\mathrm{pH}_{\mathrm{eq}} \sim 3$ for the same reason (decrease in repulsion effects); however, at higher $\mathrm{pH}$ the formation of large size polynuclear hydrolyzed species limits the accessibility to internal reactive groups for uranyl species. The substantial increase in sorption performance between PA6 large particles and PA6/n-HAp is probably associated to the higher accessibility of reactive groups induced by the fractionation of the polymer microparticles (average particle size 602 $\mathrm{nm}$ ) into small nanoparticles (i.e., $66 \mathrm{~nm}$ ). On the other side, the uptake of a polynuclear uranyl species means that the binding of one molecule induces the sorption of several $U$ atoms ( $2-4$, see Fig. S8). The formation of polynuclear species enhances the surface sorption but may limits the diffusion and accessibility to internal sites.

Fig. S9a shows the $\log _{10}$ plot of the distribution ratio $\left(\mathrm{D}=\mathrm{q}_{\mathrm{eq}} / \mathrm{C}_{\mathrm{eq}}, \mathrm{L}\right.$ $\mathrm{g}^{-1}$ ) vs equilibrium $\mathrm{pH}$. A breakdown of the slope of theses curves is observed at pH close to 3: slope inversion for U(VI) and slope changes for REEs. The plots of the distribution curves show only linear sections with $\mathrm{U}(\mathrm{VI})$. The slope of the linear segments may be associated in ionexchange processes to the stoichiometry of proton exchange with metal cations. Actually, the stoichiometric ratios for U(VI) on PA6/n$\mathrm{HAp}$ are +0.74 and -0.76 before and after $\mathrm{pH}_{\mathrm{eq}} 3$, respectively. These values are "close" to 1 ; this is not consistent with the predominant uranyl species in this $\mathrm{pH}$ range (i.e., free $\mathrm{UO}_{2}^{2+}$ ). Fig. $\mathrm{S} 9 \mathrm{~b}$ shows the comparison of equilibrium and initial $\mathrm{pH}$ values during metal sorption for both PA6 and PA6/n-HAp. The variation of $\mathrm{pH}$ is negligible, meaning that proton exchange is not the predominant binding mechanism.

\subsubsection{Sorbent dosage - Optimization of sorbent dosage (SD)}

Fig. 4 compares the effect of sorbent dosage on the sorption efficiency and the sorption capacity for the three metals using both PA6 and $\mathrm{PA6} / \mathrm{n}$-HAp. These experiments were performed at $\mathrm{pH}_{0} 2.04$ using multi-element solutions. The speciation diagram is hardly affected by the ternary composition of the solution (not shown): free rare earths and free uranyl are largely predominating in the solution at $\mathrm{pH} 2-2.5$. This figure clearly confirm the beneficial effect of the incorporation of n-HAp in the sorption performance of the composite. The sorption efficiency curves are almost superposed in the case of PA6 for the three metals: the sorption progressively increases with sorbent dosage from $5-8 \%$ to $22-28 \%$. As expected, the increase of the SD results in a progressive decrease in sorption capacity (never exceeding $0.13 \mathrm{mmol}^{\text {metal } \mathrm{g}^{-1}}$ under selected experimental conditions). The same trends are observed with composite sorbent: the sorption efficiency increases with SD and tends to stabilize above $\mathrm{SD}=1 \mathrm{~g} \mathrm{~L}^{-1}$ at least for REEs; indeed, the solution is almost exhausted in terms of $\mathrm{Nd}(\mathrm{III})$ and $\mathrm{Er}(\mathrm{III})$ concentrations. As usual, the sorption capacities decrease with increasing SD. In this case again, the affinity of the sorbent tends to decrease according the series: $\mathrm{Nd}(\mathrm{III})>\mathrm{Er}(\mathrm{III})>\mathrm{U}(\mathrm{VI})$. Obviously, this conclusion should be moderated since the mass concentration for each individual metal (i.e., $50 \mathrm{mg}$ $\mathrm{L}^{-1}$ ) means that molar concentration of $\mathrm{U}(\mathrm{VI})$ is lower than for the two REEs (i.e., $0.201 \mathrm{mmol} \mathrm{U} \mathrm{L}^{-1}, 0.361 \mathrm{mmol} \mathrm{Nd} \mathrm{L}^{-1}$ and $0.302 \mathrm{mmol} \mathrm{Er}$ $\mathrm{L}^{-1}$ ). The ranking of metal affinities will be analyzed through sorption isotherms (see Section 3.2.4.). Under selected experimental conditions (especially range of concentrations that are consistent with real industrial solutions and leachates) a good compromise for removal efficiency and sorption capacity would consist of SD: $1 \mathrm{~g} \mathrm{~L}^{-1}$.

\subsubsection{Uptake kinetics - Mass transfer limitations}

The uptake kinetics are compared in Fig. 5 for the different systems (sorbent and metal) from ternary solutions (containing $\sim 50 \mathrm{mg} \mathrm{L}^{-1}$ ) at $\mathrm{pH}_{0}$ 2.04. This figure clearly illustrates again the beneficial effect of the incorporation of n-HAp in the composite sorbents not only in terms of sorption performance at equilibrium but also in terms of kinetic profiles, for the three metals. Under selected experimental conditions, SD: $1 \mathrm{~g}$ $\mathrm{L}^{-1}$, the sorption efficiency never exceeds $20 \%$ with PA6 sorbent while metal removal varies between $96 \%$ for $\mathrm{Nd}(\mathrm{III})$ and $80 \%$ for U(VI) $(90 \%$ for Er(III)) in the case of PA6/n-HAp. Despite a higher density of amide groups in PA6 (compared with the composite) the metal binding is
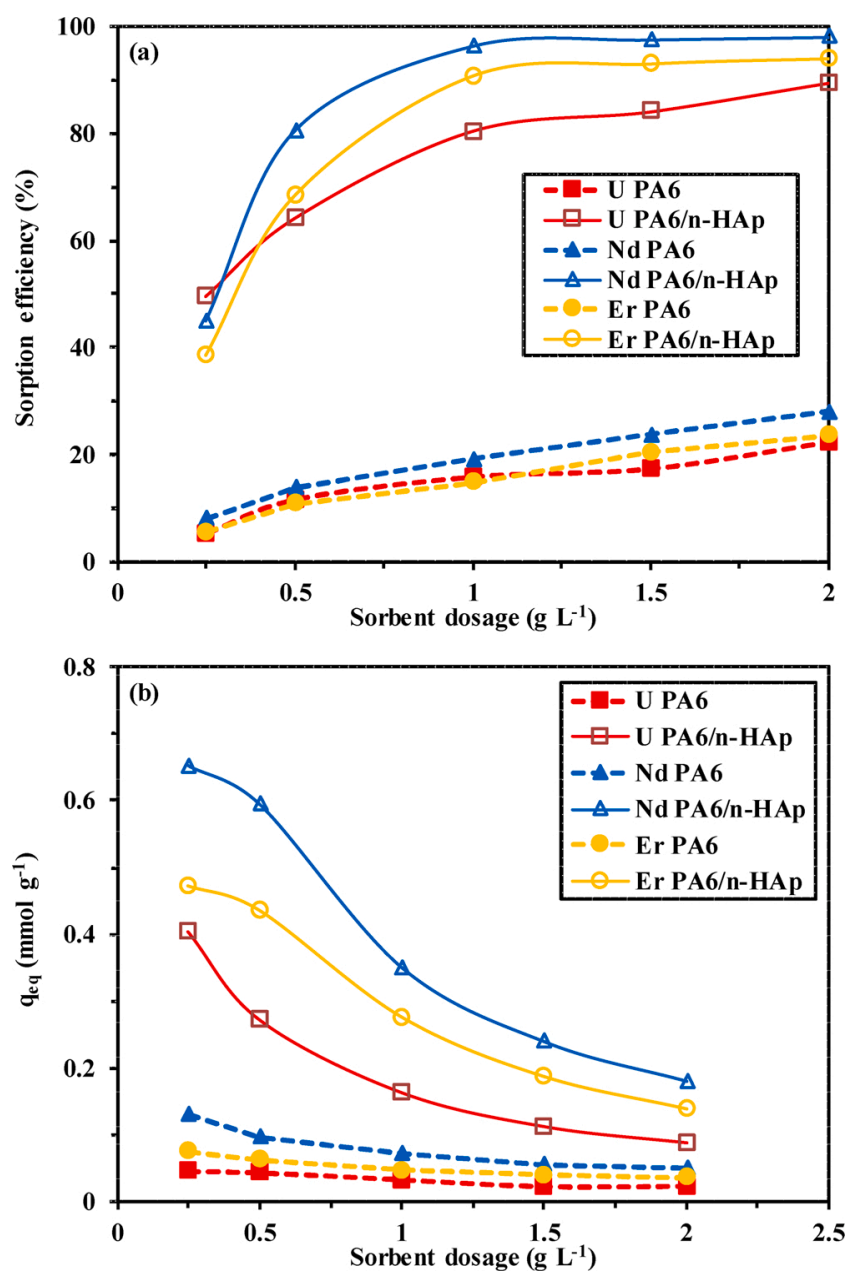

Fig. 4. Effect of sorbent dosage on U(VI), Nd(III) and Er(III) sorption efficiency (a) and sorption capacity (b) (multicomponent solutions; Sorbent dosage, SD: 0.25-2 $\mathrm{g} \mathrm{L}^{-1} ; \mathrm{C}_{0}$ : $50 \mathrm{mg} \mathrm{L}^{-1}, 0.205 \mathrm{mmol} \mathrm{U} \mathrm{L}^{-1}, 0.342 \mathrm{mmol} \mathrm{Nd} \mathrm{L}^{-1}$ or 0.297 mmol Er L ${ }^{-1} ; \mathrm{pH}_{0}: 2.04 ; \mathrm{pH}_{\mathrm{eq}}: 2.08 \pm 0.02$; room temperature; contact time: $24 \mathrm{~h})$.

decreased. This is a clear confirmation that all the reactive groups are not available in PA6 microparticles, while the composite offers more available and accessible sorption sites. In terms of kinetics, the shape of the profiles also confirm that the initial slopes for PA6 sorbent are much lower than are those of composite materials, regardless of the metal. As an example, in the case of PA6/n-HAp about $88 \%$ of total sorption occurs within the first two hours of contact; on the opposite hand, for the same contact time sorption represents only $58 \%$ for REEs and $66 \%$ for $\mathrm{U}$ (VI) in the case of PA6.

The kinetic profiles have been fitted with the PFORE (pseudo-first order rate equation), the PSORE (pseudo-second order rate equation) and the RIDE (resistance to intraparticle diffusion, the so-called Crank equation) (Table S1a). Table 1 reports the parameters of these models for the different systems while the solid lines in Fig. 5 shows the respective fittings. The comparison of $\mathrm{R}^{2}$ and AIC values does not allow clearly stating the preferential model for fitting experimental profiles: the selection depends on the metal and the sorbent. In the case of U(VI), the RIDE model systematically gives the best fitting accuracy. In the case of REEs and PA6, the PFORE allows getting higher values for both $\mathrm{R}^{2}$ and AIC while for PA6/n-HAp the PSORE is more efficient for Nd(III); for Er (III), both the PSORE and the RIDE give good fits. Cheira et al. concluded that U(VI) sorption onto PA6 and PA6/montmorillonite is preferentially described by the PSORE [42]. Comparing experimental values of the sorption capacity at equilibrium $\left(\mathrm{q}_{\mathrm{eq}}\right)$ with calculated values $\left(\mathrm{q}_{\mathrm{eq}, 1}\right.$ or 

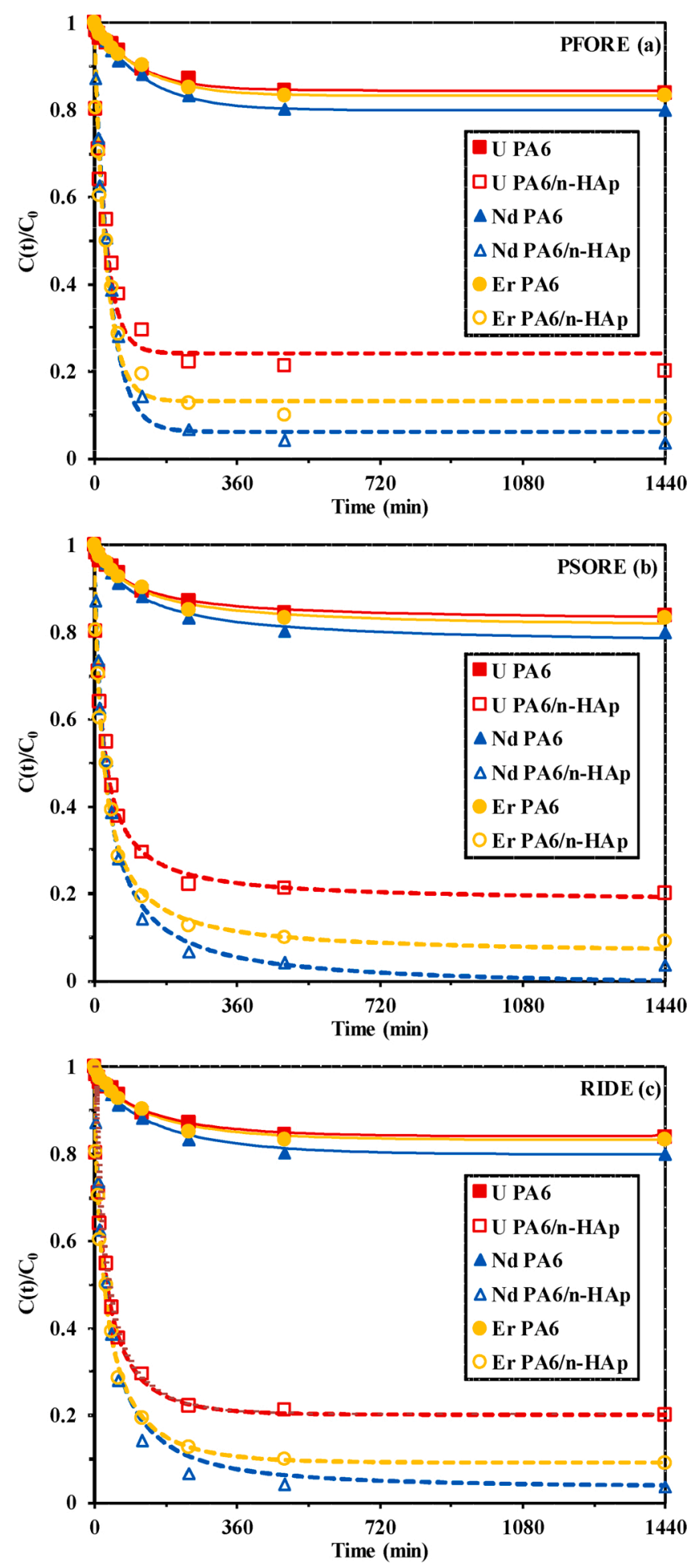

Fig. 5. Uptake kinetics for the sorption of U(VI), Nd(III) and $\operatorname{Er}(\mathrm{III})$ using PA6 and PA6/n-HAp sorbents - Modeling with the PFORE (a), PSORE (b) and the RIDE (c) equations (multicomponent solutions; Sorbent dosage, SD: $1 \mathrm{~g} \mathrm{~L}^{-1} ; \mathrm{C}_{0}$ : $50 \mathrm{mg} \mathrm{L}^{-1}, 0.205 \mathrm{mmol} \mathrm{U} \mathrm{L}^{-1}, 0.342 \mathrm{mmol} \mathrm{Nd} \mathrm{L}^{-1}$ or $0.297 \mathrm{mmol} \mathrm{Er} \mathrm{L}^{-1}$; room temperature; $\mathrm{pH}_{0}: 2.04 ; \mathrm{pH}_{\mathrm{eq}}: 2.06$ ).

$\mathrm{q}_{\mathrm{eq}, 2}$ ) shows that the PFORE gives a better approximation of experimental values. Taking into account the small size of the sorbent particles, the time required to reach equilibrium (i.e., several hours) clearly mean that the mass transfer is controlled by diffusion mechanisms, and more specifically the resistance to intraparticle diffusion. Therefore, the effective diffusivity coefficients (i.e., $\mathrm{D}_{\mathrm{e}}$ ) are very low (ranging between
Table 1

Uptake kinetics for U(VI), Nd(III) and Er(III) sorption onto PA6 and PA6/n-HAp sorbents from ternary solutions - Modeling with the PFORE, the PSORE and the RIDE.

\begin{tabular}{|c|c|c|c|c|c|c|c|}
\hline \multirow[b]{2}{*}{ Model } & \multirow{2}{*}{$\begin{array}{l}\text { Sorbent } \\
\text { Metal }\end{array}$} & \multicolumn{3}{|l|}{ PA6 } & \multicolumn{3}{|c|}{ PA6/n-HAp } \\
\hline & & $\mathrm{U}(\mathrm{VI})$ & $\begin{array}{l}\mathrm{Nd} \\
\text { (III) }\end{array}$ & $\begin{array}{l}\text { Er } \\
\text { (III) }\end{array}$ & $\mathrm{U}(\mathrm{VI})$ & $\begin{array}{l}\mathrm{Nd} \\
\text { (III) }\end{array}$ & $\begin{array}{l}\text { Er } \\
\text { (III) }\end{array}$ \\
\hline \multirow[t]{2}{*}{ Exper. } & $\begin{array}{l}\mathrm{q}_{\mathrm{eq}}(\mathrm{mmol} \\
\left.\mathrm{g}^{-1}\right)\end{array}$ & 0.032 & 0.073 & 0.051 & 0.160 & 0.349 & 0.274 \\
\hline & $\begin{array}{l}\mathrm{q}_{\mathrm{eq}, 1}(\mathrm{mmol} \\
\left.\mathrm{g}^{-1}\right)\end{array}$ & 0.031 & 0.072 & 0.051 & 0.152 & 0.339 & 0.262 \\
\hline \multirow[t]{4}{*}{ PFORE } & $\begin{array}{l}\mathrm{k}_{1} \times 10^{2} \\
\left(\min ^{-1}\right)\end{array}$ & 0.94 & 0.81 & 0.85 & 3.45 & 2.61 & 3.17 \\
\hline & $\mathrm{R}^{2}$ & 0.986 & 0.997 & 0.995 & 0.975 & 0.991 & 0.982 \\
\hline & AIC & -101 & -116 & -114 & -62 & -69 & -63 \\
\hline & $\begin{array}{l}\mathrm{q}_{\mathrm{eq}, 2}(\mathrm{mmol} \\
\left.\mathrm{g}^{-1}\right) \\
\mathrm{k}_{2} \times 10^{1}(\mathrm{~g}\end{array}$ & 0.035 & 0.083 & 0.058 & 0.164 & 0.368 & 0.284 \\
\hline \multirow[t]{4}{*}{ PSORE } & $\begin{array}{l}\mathrm{mmol}^{-1} \\
\left.\min ^{-1}\right)\end{array}$ & 3.19 & 1.11 & 1.72 & 3.06 & 0.97 & 1.59 \\
\hline & $\mathrm{R}^{2}$ & 0.987 & 0.992 & 0.988 & 0.995 & 0.995 & 0.996 \\
\hline & AIC & -105 & -104 & -105 & -82 & -77 & -81 \\
\hline & $\begin{array}{l}\mathrm{D}_{\mathrm{e}} \times 10^{17}\left(\mathrm{~m}^{2}\right. \\
\left.\min ^{-1}\right)\end{array}$ & 13.4 & 11.6 & 12.9 & 0.209 & 0.034 & 0.097 \\
\hline \multirow[t]{2}{*}{ RIDE } & $\mathrm{R}^{2}$ & 0.991 & 0.994 & 0.994 & 0.998 & 0.993 & 0.993 \\
\hline & AIC & -113 & 104 & -110 & -90 & -71 & -84 \\
\hline
\end{tabular}

$1.34 \times 10^{-16} \mathrm{~m}^{2} \mathrm{~min}^{-1}$ and $3.4 \times 10^{-19} \mathrm{~m}^{2} \mathrm{~min}^{-1}$ ). This means several orders of magnitude than the values reported for the self-diffusivity of metal ions in water [85] (around $4.8 \times 10^{-8} \mathrm{~m}^{2} \mathrm{~min}^{-1}$ for $\mathrm{U}(\mathrm{VI}), 3.45 \times$ $10^{-8} \mathrm{~m}^{2} \mathrm{~min}^{-1}$ for $\mathrm{Nd}(\mathrm{III})$, and $3.48 \times 10^{-8} \mathrm{~m}^{2} \mathrm{~min}^{-1}$ for $\mathrm{Er}(\mathrm{III})$ ). In the study of Er(III) diffusion in porous sol-gel glass, Koone et al. [86] reported the correlation between diffusivity coefficients and parameters such as REE ionic size and hydration number. Herein, the relatively higher diffusivity coefficient for $\mathrm{Er}(\mathrm{III})$ compared with $\mathrm{Nd}(\mathrm{III})$ is consistent with this explanation. The diffusion is controlled by size of ionic species in relation with the size of pores; this effect is highlighted, in the case of non-adsorbing conditions, by the so-called Renkin equation [87]. The BET analysis showed that the incorporation of n-HAp allows slightly increasing the average pore size (from 2.2 to $2.6 \mathrm{~nm}$ ); this is not enough for making substantial differences in the mass transfer of REEs(III) and U(VI). Under selected experimental conditions (i.e., $\mathrm{pH}$ 2.44) uranyl (in its hydrated from) is present as free divalent cation with an ionic radius close to $1.08 \AA$ intermediary between the values of $\mathrm{Nd}$ (III) (i.e., $1.16 \AA$ ) and $\operatorname{Er}(\mathrm{III})$ (i.e., 1.01 $\AA$ ) [88]. However, the effective diffusivity in the sorbents is higher for uranyl than for REEs, especially for PA6/n-HAp. This is consistent with the values of the apparent rate coefficients (both $\mathrm{k}_{1}$ and $\mathrm{k}_{2}$ parameters), which systematically follow the sequence: $\mathrm{U}(\mathrm{VI})>\mathrm{Er}(\mathrm{III})>\mathrm{Nd}(\mathrm{III})$. Divalent uranyl cation $\left(\mathrm{UO}_{2}\left(\mathrm{H}_{2} \mathrm{O}\right)_{5}^{2+}\right)$, with lower hydration number [88], appears to be more readily transferred and sorbed in the sorbents than trivalent rare earth cations (as $\mathrm{Nd}\left(\mathrm{H}_{2} \mathrm{O}\right)_{9}^{3+}$ and $\mathrm{Er}\left(\mathrm{H}_{2} \mathrm{O}\right)_{8.96}^{3+}$ ).

Low specific surface area PA6, with small pores, shows weak mass transfer properties requiring long contact time for reaching equilibrium. These limitations to mass transfer reduce the accessibility to internal reactive groups. This means that sorbent particles should be decreased to improve mass transfer and reactivity. This is also achieved by the melt compounding of PA6 with nano particles of hydroxyapatite, as appearing in the comparison of the kinetic profiles.

\subsubsection{Sorption isotherms - equilibrium performance}

Another important criterion for evaluating the properties of the sorbent consists of the sorption isotherm that plots the distribution of the solute at equilibrium between the liquid and solid phase at a given $\mathrm{pH}$ and temperature for increasing metal concentrations. The sorption isotherm provides two important insights: (a) the maximum sorption capacity achieved at saturation of the sorbent (the plateau appearing in Fig. 6), and (b) the affinity of the sorbent for the solute (approached by 


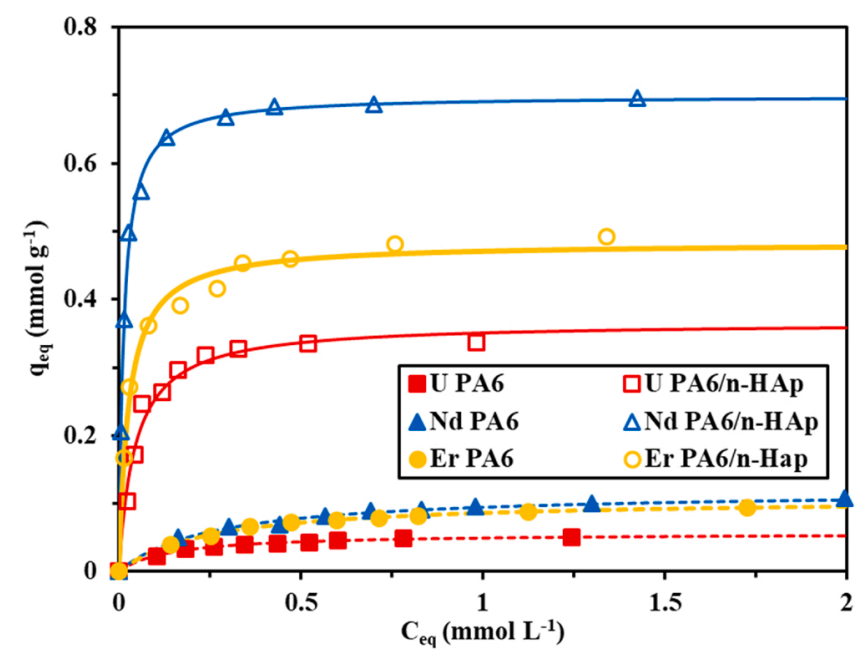

Fig. 6. U(VI), $\mathrm{Nd}(\mathrm{III})$ and $\mathrm{Er}(\mathrm{III})$ sorption isotherms using PA6 and PA6/n-HAp (multicomponent solutions; Sorbent dosage, SD: $1 \mathrm{~g} \mathrm{~L}^{-1}$; $\mathrm{C}_{0}$ : $30-300 \mathrm{mg} \mathrm{L}^{-1}$, 0.12-1.2 $\mathrm{mmol} \mathrm{U} \mathrm{L}^{-1}, 0.13-1.30 \mathrm{mmol} \mathrm{Nd} \mathrm{L}{ }^{-1}$ or $0.182-1.82 \mathrm{mmol} \mathrm{Er} \mathrm{L}{ }^{-1} ; \mathrm{pH}_{0}$ : 2.04; $\mathrm{pH}_{\mathrm{eq}}: 2.04 \pm 0.03$; room temperature; contact time: $24 \mathrm{~h}$; solid lines: modeling with the Langmuir equation and parameters summarized in Table 2).

the initial slope of the curves in Fig. 6). The comparison of U(VI), Er(III) and $\mathrm{Nd}$ (III) sorption isotherms for PA6 and PA6/n-HAp confirms the drastic improvement of sorption performance while incorporating $n$ HAp: the maximum sorption capacities are increased 6.6, 6.5 and 5.2 times for $\mathrm{U}(\mathrm{VI}), \mathrm{Nd}(\mathrm{III})$ and $\mathrm{Er}(\mathrm{III})$, respectively. In addition, the initial slope of the isotherms is higher for composite material. Again, the sorbents show preference for metal ions according the series: $\mathrm{Nd}(\mathrm{III})>\mathrm{Er}$ (III) $>\mathrm{U}(\mathrm{VI})$. Table 2 compares the fits of sorption isotherms (performed in ternary solutions) with the Langmuir, the Freundlich and the Sips equations (Table S1b). The asymptotic shape of the sorption isotherm corresponds to the saturation of the sorbent, which, in turn, explains that the Freundlich equation (a power-type function, supposed to describe multi-layer sorption with heterogeneous sorption energies) is not appropriate for describing metal sorption on both PA6 and PA6/nHAp. The Sips equation (Langmuir-Freundlich concept) introduces a third-adjustable parameter, which is supposed to improve the quality of curve fitting; this is confirmed by the higher $\mathrm{R}^{2}$ values. However, the AIC takes into account the effect of number of adjustable parameters and shows that, in most cases, the Langmuir equation better describes experimental profiles (the unique exception concerns $\mathrm{U}(\mathrm{VI})$ sorption onto PA6/n-HAp, which is better fitted by the Sips equation). The Langmuir equation supposes the sorption to occur as a monolayer, with no interactions between sorbed molecules and homogeneous sorption energies. The sorption capacities at saturation of monolayer (i.e., $\mathrm{q}_{\mathrm{m}, \mathrm{L}}$ ) are roughly consistent (slightly overestimated, except for Er(III) onto PA6/n-HAp) with the experimental values of maximum sorption capacities. The affinity coefficients (i.e., $\mathrm{b}_{\mathrm{L}}$ ) are substantially increased for PA6/n-HAp compared with PA6: by 3.3 for U(VI), 9.5 for Er(III) and up to 20.5 for $\mathrm{Nd}(\mathrm{III})$. The ranking of affinity coefficients follows the same order than maximum sorption capacities: $\mathrm{Nd}(\mathrm{III})>\mathrm{Er}(\mathrm{III})>\mathrm{U}(\mathrm{VI})$ for PA6/n-HAp (contrary to PA6: U(VI) > Er(III) Nd(III)). Uranyl and rare earths are classified as hard acids according the Pearson rules [89]; they are supposed to be preferentially bound to hard bases (bearing $\mathrm{O}$ - and $\mathrm{N}$ donor ligands, for example as in PA6-based materials). Trivalent cations are usually considered having a more pronounced hard behavior; the hardness being also modulated by the ionic size of the metal. According these rules neodymium is the harder of the three metals, which may explain its higher affinity for PA6/n-HAp; for the ranking of Er(III) and U (VI), apparently the charge criterion is more important than the ion size impact. The covalent index (CI: $\chi^{2} / \mathrm{r}$, with $\chi$ the Pauling electronegativity and $r$ the covalent radius) and the ionic index (II: $\mathrm{Z}^{2} / \mathrm{r}$, with $\mathrm{Z}$ the ion formal charge) can be used for ranking the three metals ions. The order of affinity and sorption of the metal ions for PA/n-HAp follows the reciprocal trend of the CI: $\mathrm{Nd}$ (III) (0.69) < $\operatorname{Er}(\mathrm{III})(0.87)<\mathrm{U}(\mathrm{VI})(1.58)$; contrary to the II that does not show any correlation in trends: U(VI) (2.19) $<\mathrm{Nd}$ (III) (4.79) < $\mathrm{Er}$ (III) (5.08). Apparently, the covalent nature is more important than the ionic criterion for explaining the affinity of the sorbent for selected metal ions.

Table S4 summarizes sorption properties for Nd(III), Er(III) and U (VI) for alternative sorbents. The comparison with PA6/n-HAp shows that several sorbents are more efficient than the present composites. However, it is noteworthy that these most efficient sorbents are generally designed for the sorption of target metals at less acidic $\mathrm{pH}$ values. Considering the sorption properties for acidic solutions (consistent with the application to metal recovery from acidic leachates) PA6/n-HAp is part of the most efficient materials. Typically, for $\mathrm{U}(\mathrm{VI})$ the maximum sorption capacity is comparable with those of commercial resins [21]. For REEs, the composite exhibits very attractive sorption properties at $\mathrm{pH}$ 2.44; comparable to most of the sorbents reported. The alternative sorbents having higher sorption capacities require higher $\mathrm{pH}$ values for reaching outstanding sorption capacities.

\subsubsection{Metal desorption - Selection of eluent}

Designing a new sorbent and a sorption process also requires optimizing the metal desorption for valorizing the metal, concentrating the hazardous contaminant and for recycling the sorbent. The study of metal desorption was performed playing with different acidic eluents at different concentrations. Fig. 7 compares desorption performances for these eluents for PA6/n-HAp after metal loading (in ternary solutions). The sorbent contained initially the following metal loadings: $0.36 \mathrm{mmol}$ $\mathrm{Nd} \mathrm{g}^{-1}, 0.28 \mathrm{mmol} \mathrm{Er} \mathrm{g}^{-1}$ and $0.16 \mathrm{mmol} \mathrm{U} \mathrm{g}^{-1}$. As expected, the two rare earths have very comparable responses to type and concentration of

Table 2

U(VI), Nd(III) and Er(III) sorption isotherms using n-HAp and PA6/nHAp sorbents - Modeling with Langmuir, Freundlich and Sips equations.

\begin{tabular}{|c|c|c|c|c|c|c|c|}
\hline \multirow{2}{*}{ Model } & \multirow{2}{*}{ Parameter } & \multicolumn{3}{|l|}{ PA6 } & \multicolumn{3}{|c|}{ PA6/n-HAp } \\
\hline & & $\mathrm{U}(\mathrm{VI})$ & $\mathrm{Nd}(\mathrm{III})$ & $\operatorname{Er}(\mathrm{III})$ & $\mathrm{U}(\mathrm{VI})$ & $\mathrm{Nd}(\mathrm{III})$ & Er(III) \\
\hline \multirow[t]{2}{*}{ Experim. } & $\mathrm{q}_{\mathrm{m}}\left(\mathrm{mmol} \mathrm{g}^{-1}\right)$ & 0.051 & 0.107 & 0.094 & 0.336 & 0.697 & 0.492 \\
\hline & $\mathrm{q}_{\mathrm{m}, \mathrm{L}}\left(\mathrm{mmol} \mathrm{g}^{-1}\right)$ & 0.056 & 0.120 & 0.107 & 0.367 & 0.700 & 0.483 \\
\hline \multirow{3}{*}{ Langmuir } & $\mathrm{R}^{2}$ & 0.995 & 0.994 & 0.998 & 0.984 & 0.996 & 0.991 \\
\hline & AIC & -133 & -116 & -127 & -80 & -80 & -79 \\
\hline & $\mathrm{k}_{\mathrm{F}}$ & 0.051 & 0.092 & 0.085 & 0.385 & 0.742 & 0.510 \\
\hline \multirow{3}{*}{ Freundlich } & $\mathrm{n}$ & 3.68 & 3.48 & 3.32 & 4.76 & 7.03 & 5.64 \\
\hline & $\mathrm{q}_{\mathrm{m}, \mathrm{S}}\left(\mathrm{mmol} \mathrm{g}^{-1}\right)$ & 0.058 & 0.135 & 0.105 & 0.340 & 0.697 & 0.517 \\
\hline & $\mathrm{b}_{\mathrm{S}}\left(\mathrm{L} \mathrm{mmol}^{-1}\right)$ & 5.80 & 2.36 & 4.40 & 103.2 & 93.2 & 14.2 \\
\hline \multirow[t]{3}{*}{ Sips } & $\mathrm{n}_{\mathrm{s}}$ & 1.07 & 1.27 & 0.969 & 0.690 & 0.963 & 1.32 \\
\hline & $\mathrm{R}^{2}$ & 0.995 & 0.996 & 0.998 & 0.993 & 0.997 & 0.995 \\
\hline & AIC & -129 & -115 & -123 & -84 & -76 & -71 \\
\hline
\end{tabular}




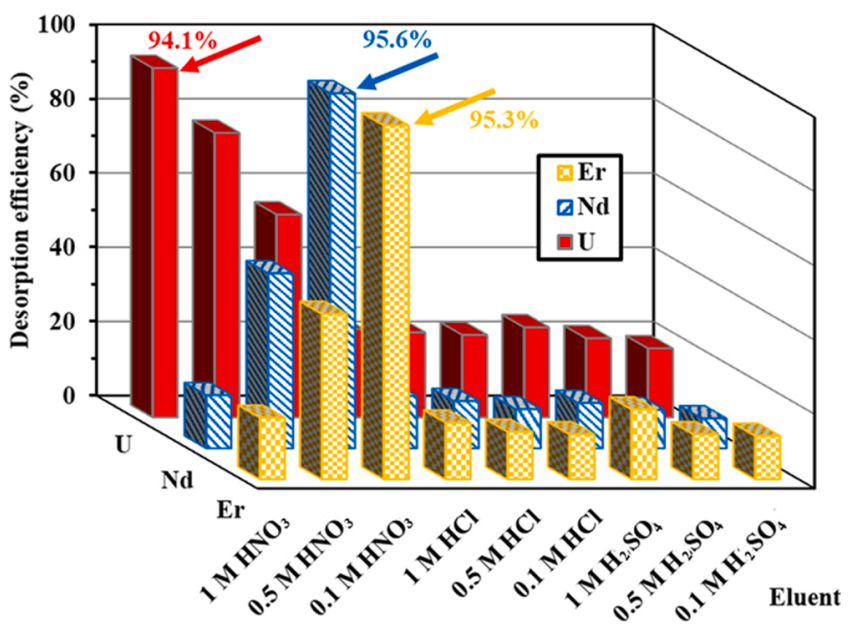

Fig. 7. Effect of the eluent (type and concentration) on U(VI), Nd(III) and Er (III) desorption from metal-loaded PA6/n-HAp sorbent (SD for both metal loading and desorption test: $1 \mathrm{~g} \mathrm{~L}^{-1}$; room temperature, contact time: $24 \mathrm{~h}$; multicomponent solutions for metal loading at $\mathrm{C}_{0}: 50 \mathrm{mg} \mathrm{L}^{-1}$ at $\mathrm{pH}_{0}: 2.04$ ).

acids in terms of desorption efficiency: the most efficient eluent consists of $0.1 \mathrm{M} \mathrm{HNO}_{3}$ solution and the elution yield reaches $95.3-95.6 \%$. A higher nitric acid concentration is required for the elution of $\mathrm{U}(\mathrm{VI})$ : uranyl desorption reaches $94.1 \%$ for $1 \mathrm{M} \mathrm{HNO}_{3}$ solution. For separating the different metals, the suggested sequence would consist of: (a) first desorption of $\mathrm{U}(\mathrm{VI})$ with $1 \mathrm{M} \mathrm{HNO}_{3}$ solution ( $\mathrm{Nd}$ and Er elution remains below $17 \%$ ), followed by (b) the desorption of REEs using $0.1 \mathrm{M} \mathrm{HNO}_{3}$ solution. The reverse sequence appears inappropriate since the 0.1 $\mathrm{MHNO}_{3}$ solution removes about $55 \%$ of bound uranyl, simultaneously to $95 \%$ of REEs.

The elution of the metal-loaded sorbent with $0.1 \mathrm{M} \mathrm{HNO}_{3}$ solution is supposed to produce an eluate with enriched REE concentration containing much lower concentrations of uranyl. The separation of REEs from U(VI) would be readily operated using oxalic acid for the selective precipitation (and valorization) of REEs [90].

\subsubsection{Sorbent recycling}

Table 3 reports the performances of U(VI), Nd(III) and Er(III) sorption and desorption for PA6/n-HAp during 5 successive sorption/ desorption cycles. The desorption efficiency remains remarkably stable for the 5 cycles: around $94.5 \pm 0.5 \%, 95.1 \pm 1.0 \%$ and $94.8 \pm 0.6 \%$ for $\mathrm{U}(\mathrm{VI}), \mathrm{Nd}(\mathrm{III})$ and $\mathrm{Er}(\mathrm{III})$, respectively. The three metals are similarly desorbed using $1 \mathrm{M} \mathrm{HNO}_{3}$ for uranyl and $0.1 \mathrm{M} \mathrm{HNO}_{3}$ for REEs. The differences are more marked in the case of sorption performance: U(VI) (i.e., $75.9 \pm 4.1 \%$ ) $<\operatorname{Er}(\mathrm{III})$ (i.e;, $88.0 \pm 2.5 \%$ ) $<\mathrm{Nd}$ (III) (i.e., $94.9 \pm$ $1.9 \%)$. The sorption of REEs on PA6/n-HAp is more robust than the recovery of $\mathrm{U}(\mathrm{VI})$ : the sorption performance remain relatively stable for the first 4 cycles and slightly decreases at the fifth; contrary to U(VI) uptake that continuously decreases for the 5 cycles. However, it is worth noting that the sorption loss is limited to $14 \%$ for U(VI), $8 \%$ for $\operatorname{Er}(\mathrm{III})$ and only $5 \%$ for $\mathrm{Nd}(\mathrm{IIII})$ at the last cycle. It is noteworthy that the sorbent loss during the successive sorption and desorption steps was negligible (less than $5 \%$ ): the material is stable. This is consistent with the recycling performances reported for many alternative sorbents. This also demonstrates the feasibility of sorbent recycling.

\subsubsection{Application to metal recovery from acid leachate of ore - Effect of solution complexity}

The working solution for the simulation of industrial application was obtained from the leaching of El-Sella uranium ore using sulfuric acid solution. Ore was grinded and the fraction of particle size lower than 74 $\mu \mathrm{m}(200 \mathrm{Mesh})$ was collected. A $10 \% \mathrm{w} / \mathrm{w}$ sulfuric acid solution was used for leaching tests with a solid/liquid mass ratio of 1:2, a stirring time of $240 \mathrm{~min}$ (stirring speed: $300 \mathrm{rpm}$ ), at a temperature of $45{ }^{\circ} \mathrm{C}$ [67]. The composition of leachate is summarized in Table 4, together with the residual concentrations after sorption test using PA6/n-HAp. The leachates contain three major metal elements: aluminum, iron and sodium. Iron concentration is slightly decreased after sorption while for aluminum and sodium the loss of metal ions is negligible. Phosphate and sulfate content are not affected by the contact with the sorbent. Other significant constituents are uranium and REEs. The global index of REEs (measured by the spectrophotometric method) shows that the sorption process is highly efficient: the desorption yield reaches $94 \%$, the sorption capacity corresponds to $90.2 \mathrm{mg} \mathrm{REE}_{\mathrm{eq}} \mathrm{g}^{-1}$. It is noteworthy that the distribution ratio (i.e., D) is higher than 15 , as a clear confirmation of the affinity of the sorbent for REEs in complex solutions. The sorption capacity for $\mathrm{U}(\mathrm{VI})$ does not exceed $0.315 \mathrm{mmol} \mathrm{U} \mathrm{g}^{-1}$ (i.e., 75 $\mathrm{mg} \mathrm{g}^{-1}$ ). This value is close to the maximum sorption capacity found with ternary pure solutions (Table 2); the loss in sorption capacity does not exceed $7 \%$. Despite the complexity of the leachate (high ionic strength), the sorbent maintains good sorption performance for U(VI). The high relative concentration of the metal in the leachate does not allow reaching high distribution ratio (close to 0.37). It is noteworthy that thorium (frequently associated with uranium) is strongly adsorbed onto PA6/n-HAp: sorption efficiency exceeds $86 \%$ and the distribution ratio reaches up to 6.5. The similarity in chemical properties between Th (IV) and U(VI) can explain the good uptake of thorium. Other base metals (such as copper and nickel) are also present in the leachate at concentrations around $12-13 \mathrm{mg} \mathrm{L}^{-1}$; their removal is rather limited (efficiency in the range 16-29\%) and the sorption capacities range between 0.03 and $0.06 \mathrm{mmol} \mathrm{g}^{-1}$. This means that the sorbent has a

\section{Table 4}

Recovery of REEs and uranium from acidic leachate of Egyptian ore (El Sella mining area) by sorption onto PA6/n-HAP.

\begin{tabular}{lllllll}
\hline Compd. & $\begin{array}{l}\mathrm{C}_{0} \\
(\mathrm{mg} \\
\left.\mathrm{L}^{-1}\right)\end{array}$ & $\begin{array}{l}\mathrm{C}_{\mathrm{eq}} \\
(\mathrm{mg}\end{array}$ & $\begin{array}{l}\left.\mathrm{L}^{-1}\right) \\
\text { Sorption } \\
(\%)\end{array}$ & $\begin{array}{l}\text { Sorption } \\
\text { capacity } \\
\left(\mathrm{mg} \mathrm{g}^{-1}\right)\end{array}$ & $\begin{array}{l}\text { Sorption } \\
\text { capacity } \\
(\mu \mathrm{mol} \\
\left.\mathrm{g}^{-1}\right)\end{array}$ & $\begin{array}{l}\text { Distribution } \\
\text { ratio, D (L } \\
\left.\mathrm{g}^{-1}\right)\end{array}$ \\
\hline $\mathrm{Fe}(\mathrm{III})$ & 1272 & 1200 & 5.7 & 72 & 1289.17 & 0.06 \\
$\mathrm{~S}(\mathrm{VI})$ & 1341 & 1339 & 0.15 & 2 & 62.5 & Negl \\
$\mathrm{P}(\mathrm{V})$ & 76 & 75 & 1.3 & 1 & 32.29 & 0.01 \\
$\mathrm{Al}(\mathrm{III})$ & 2900 & 2898 & 0.07 & 2 & 74.13 & Negl \\
$\mathrm{Na}(\mathrm{I})$ & 980 & 979 & 0.1 & 1 & 43.48 & Negl \\
$\mathrm{Cu}(\mathrm{II})$ & 13.0 & 9.2 & 29.2 & 3.8 & 59.8 & 0.413 \\
$\mathrm{Ni}(\mathrm{II})$ & 12.0 & 10.1 & 15.8 & 1.9 & 32.4 & 0.188 \\
$\mathrm{Th}(\mathrm{IV})$ & 6.0 & 0.8 & 86.7 & 5.2 & 22.4 & 6.5 \\
$\mathrm{U}(\mathrm{VI})$ & 280 & 205 & 26.8 & 75 & 315.1 & 0.366 \\
$\mathrm{REEs}{ }^{\mathrm{a}}$ & 96 & 5.8 & 94.0 & 90.2 & - & 15.6 \\
\hline
\end{tabular}

${ }^{a}$ global index, analyzed by spectrophotometry; Negl: negligible $(\leq 0.001)$. $\left(\mathrm{pH}_{0}\right.$ : 1.96; contact time: 480 min; room temperature; SD: $\left.1 \mathrm{~g} \mathrm{~L}^{-1}\right)$.

Table 3

Sorption (S) and desorption (D) efficiencies (\%) for U(VI), Nd(III) and Er(III) recovery from ternary solutions over five successive cycles.

\begin{tabular}{|c|c|c|c|c|c|c|c|c|c|c|}
\hline \multirow{2}{*}{$\begin{array}{l}\text { Cycle } \\
\text { Op. }\end{array}$} & \multicolumn{2}{|c|}{ Run \#1 } & \multicolumn{2}{|c|}{ Run \#2 } & \multicolumn{2}{|c|}{ Run \#3 } & \multicolumn{2}{|c|}{ Run \#4 } & \multicolumn{2}{|c|}{ Run \#5 } \\
\hline & $S$ & $\mathrm{D}$ & $S$ & $\mathrm{D}$ & $S$ & $\mathrm{D}$ & $S$ & $\mathrm{D}$ & $S$ & $\mathrm{D}$ \\
\hline $\mathrm{U}(\mathrm{VI})$ & 80.3 & 94.4 & 79.6 & 94.9 & 76.9 & 94.1 & 73.6 & 95.1 & 69.2 & 93.9 \\
\hline $\mathrm{Nd}(\mathrm{III})$ & 96.4 & 95.8 & 96.1 & 96.1 & 95.7 & 95.3 & 95.2 & 94.9 & 91.3 & 93.2 \\
\hline Er(III) & 90.2 & 95.1 & 89.7 & 95.2 & 88.7 & 94.7 & 88.2 & 95.2 & 83.3 & 93.6 \\
\hline
\end{tabular}


marked preference for target metals: REEs and $\mathrm{U}$ family metal ions against base metals.

This preliminary test confirms that PA6/n-HAp has a broad affinity for metal ions (binding REEs, $U$ and analogues, base metals) but even in complex solutions (containing aluminum, iron, sodium, phosphate and sulfate in large concentrations) the sorbent has a marked preference for $\mathrm{U}$, Th and REEs over base metals, and alkaline metals.

\section{Conclusion}

The incorporation of a small fraction of hydroxyapatite nanoparticles (about $20 \%, \mathrm{w} / \mathrm{w}$ ) into PA6, via melt compounding, contributes to significantly improving the sorption properties of the polymer for the sorption of a series of metal cations (such as uranyl and rare earth elements) in acidic solutions. Hydrogen bonding between hydroxyl groups of hydroxyapatite and amide groups of the polymer is responsible of the stability of composite material. The composite material having a nanometer size (close to $67 \mathrm{~nm}, v s .602 \mathrm{~nm}$ for PA6) increases the availability and accessibility of reactive groups ( $-\mathrm{C}=\mathrm{O}$ and $-\mathrm{NH}$ groups) compared with single PA6. The optimum $\mathrm{pH}$ for the sorption of uranium and REEs (Nd for light REEs and Er for heavy REEs) is found close to 2-2.5. The binding mechanism is attributed to complexation of free cations by amide groups. The preference in sorption (Nd(III) $>\operatorname{Er}(\mathrm{III})>\mathrm{U}(\mathrm{VI})$ ) appears to be correlated to the covalent rather than ionic character of these metal ions. Maximum sorption capacities $\left(0.336 \mathrm{mmol} \mathrm{U} \mathrm{g}^{-1}\right.$, $0.492 \mathrm{mmol} \mathrm{Er} \mathrm{g}{ }^{-1}$, and $0.697 \mathrm{mmol} \mathrm{Nd} \mathrm{g}^{-1}$ ) are significantly improved (by 5-7 times) compared with PA6. The sorption isotherms are finely fitted by the Langmuir equation. The uptake kinetics are controlled by the resistance to intraparticle diffusion and the profiles are fitted by the pseudo-second order rate equation.

Metal desorption is highly effective (higher than $94 \%$ ) using nitric acid. The sorbent also show good recycling properties. The sorbent is highly efficient for the recovery of U(VI), Th(IV) and REE(III)s from complex solutions such as the sulfuric acid leachate of Egyptian ores collected from El Sella mining site.

It is noteworthy that the sorbent shows good sorption properties for $\mathrm{U}(\mathrm{VI})$ and REEs in acidic conditions compared with literature; about 88 $\%$ of total sorption occurs within 120 min of mixing. These results confirm that the composite PA6/n-HAp sorbent is a good candidate for the recovery of valuable metals, even in complex media (such as acidic leachates). In addition, this work confirms that the incorporation of a small fraction of hydroxyapatite nanoparticles into PA6 allows drastically improving the potential of these PA6-based materials.

\section{CRediT authorship contribution statement}

Taha F. Hassanein: Conceptualization, Methodology, Investigation, Writing - review \& editing. Ahmed M. Masoud: Conceptualization, Methodology, Investigation, Writing - review \& editing, Supervision. Wael S. Mohamed: Conceptualization, Methodology, Investigation, Writing - review \& editing. Mohamed H. Taha: Conceptualization, Formal analysis, Writing - original draft. Eric Guibal: Data curation, Validation, Supervision, Writing - review \& editing.

\section{Declaration of Competing Interest}

The authors declare that they have no known competing financial interests or personal relationships that could have appeared to influence the work reported in this paper.

\section{Acknowledgments}

Authors thank IFE (Institut Français d'Egypte, France), Ministère des Affaires Etrangères, Ministère de l'Enseignement Supérieur et de la Recherche (France) and STDF (Science and Technology Development Fund, Egypt) for supporting the bi-lateral collaboration between NMA and IMT-Mines Ales and the funding of post-doctoral fellowship of Dr. Ahmed Masoud (at IMT-Mines Ales).

\section{Appendix A. Supplementary data}

Supplementary material related to this article can be found, in the online version, at doi:https://doi.org/10.1016/j.jece.2020.104731.

\section{References}

[1] S. Wu, L. Wang, P. Zhang, H. El-Shall, B. Moudgil, X. Huang, L. Zhao, L. Zhang, Z. Feng, Simultaneous recovery of rare earths and uranium from wet process phosphoric acid using solvent extraction with D2EHPA, Hydrometallurgy 175 (2018) 109-116, https://doi.org/10.1016/j.hydromet.2017.10.025.

[2] M. Salem, R. Souissi, F. Souissi, N. Abbes, J. Moutte, Phosphoric acid purification sludge: potential in heavy metals and rare earth elements, Waste Manage. (Oxford) 83 (2019) 46-56, https://doi.org/10.1016/j.wasman.2018.10.040.

[3] A.D. Burns, P. Abbasi, D.B. Dreisinger, Uranous sulfate precipitation as a novel hydrometallurgical process for uranium purification, Hydrometallurgy 163 (2016) 49-54, https://doi.org/10.1016/j.hydromet.2016.03.008.

[4] Y. Xiao, L. Huang, Z. Long, Z. Feng, L. Wang, Adsorption ability of rare earth elements on clay minerals and its practical performance, J. Rare Earths 34 (2016) 543-548, https://doi.org/10.1016/s1002-0721(16)60060-1.

[5] R. Liao, Z. Shi, Y. Hou, K. Zhang, J. Zhang, X. Wang, K. Cheng, L. Yang, Uranium sorption onto mullite: characteristics of isotherms, kinetics and thermodynamics, J. Earth Syst. Sci. 128 (2019), 176, https://doi.org/10.1007/s12040-019-1215-5.

[6] Y. Xie, C.L. Chen, X.M. Ren, X.X. Wang, H.Y. Wang, X.K. Wang, Emerging natural and tailored materials for uranium-contaminated water treatment and environmental remediation, Prog. Mater. Sci. 103 (2019) 180-234, https://doi. org/10.1016/j.pmatsci.2019.01.005.

[7] P. Amesh, K.A. Venkatesan, A.S. Suneesh, N. Samanta, Diethylenetriamine tethered mesoporous silica for the sequestration of uranium from aqueous solution and seawater, J. Environ. Chem. Eng. 8 (2020), https://doi.org/10.1016/j. jece.2020.103995.

[8] A.M. Masoud, M. Saeed, M.H. Taha, M.M. El-Maadawy, Uranium adsorption from Bahariya Oasis leach liquor via TOPO impregnated bentonite material; isothermal, kinetic and thermodynamic studies, Egypt. J. Chem. 63 (2020) 721-741, https:// doi.org/10.21608/ejchem.2019.13638.1843.

[9] M.K. Zahran, T.F. Hassaneen, Utilization of the Egyptian flax shives for the removal of cadmium ions from aqueous solutions, Egypt. J. Chem. 50 (2007) 247-257. EID: 2-s2.0-42449139058.

[10] A.T. Reda, D. Zhang, Sorption of metal ions from aqueous solution by sulfonated calix 4 arene intercalated with layered double hydroxide, J. Environ. Chem. Eng. 7 (2019), 103021, https://doi.org/10.1016/j.jece.2019.103021.

[11] M.M. Shehataa, W.M. Youssef, H.H. Mahmoud, A.M. Masoud, Sol-gel synthesis of $\mathrm{NiO} / \mathrm{CuO}$ nanocomposites for uptake of rare earth elements (Ho, $\mathrm{Yb}$, and $\mathrm{Sm}$ ) from aqueous solutions, Russ. J. Inorg. Chem. 65 (2020) 279-289, https://doi.org/ 10.1134/S0036023620020163.

[12] K. Kiegiel, A. Abramowska, P. Bieluszka, G. Zakrzewska-Koltuniewicz, S. Wolkowicz, Solvent extraction of uranium from leach solutions obtained in processing of Polish low-grade ores, J. Radioanal. Nucl. Chem. 311 (2017) 589-598, https://doi.org/10.1007/s10967-016-5029-5.

[13] D. Saha, S.D. Akkoyunlu, R. Thorpe, D.K. Hensley, J. Chen, Adsorptive recovery of neodymium and dysprosium in phosphorous functionalized nanoporous carbon, J. Environ. Chem. Eng. 5 (2017) 4684-4692, https://doi.org/10.1016/j. jece.2017.09.009.

[14] J. Ponou, G. Dodbiba, J.W. Anh, T. Fujita, Selective recovery of rare earth elements from aqueous solution obtained from coal power plant ash, J. Environ. Chem. Eng. 4 (2016) 3761-3766, https://doi.org/10.1016/j.jece.2016.08.019.

[15] M.G. Torkabad, A.R. Keshtkar, S.J. Safdari, Comparison of polyethersulfone and polyamide nanofiltration membranes for uranium removal from aqueous solution, Prog. Nucl. Energy 94 (2017) 93-100, https://doi.org/10.1016/j. pnucene.2016.10.005

[16] A. Rahmani-Sani, A. Hosseini-Bandegharaei, S.H. Hosseini, K. Kharghani, H. Zarei, A. Rastegar, Kinetic, equilibrium and thermodynamic studies on sorption of uranium and thorium from aqueous solutions by a selective impregnated resin containing carminic acid, J. Hazard. Mater. 286 (2015) 152-163, https://doi.org/ 10.1016/j.jhazmat.2014.12.047.

[17] N. Kabay, M. Demircioglu, S. Yayli, E. Gunay, M. Yuksel, M. Saglam, M. Streat, Recovery of uranium from phosphoric acid solutions using chelating ion-exchange resins, Ind. Eng. Chem. Res. 37 (1998) 1983-1990, https://doi.org/10.1021/ ie970518k.

[18] M.J. Page, K. Soldenhoff, M.D. Ogden, Comparative study of the application of chelating resins for rare earth recovery, Hydrometallurgy 169 (2017) 275-281, https://doi.org/10.1016/j.hydromet.2017.02.006.

[19] Z. Liu, D. Liu, Z. Cai, Y. Wang, L. Zhou, Synthesis of new type dipropyl imide chelating resin and its potential for uranium(VI) adsorption, J. Radioanal. Nucl. Chem. 318 (2018) 1219-1227, https://doi.org/10.1007/s10967-018-6143-3.

[20] K.L. Ang, D. Li, A.N. Nikoloski, The effectiveness of ion exchange resins in separating uranium and thorium from rare earth elements in acidic aqueous sulfate media. Part 2. Chelating resins, Miner. Eng. 123 (2018) 8-15, https://doi.org/ 10.1016/j.mineng.2018.04.017. 
[21] R.I. Foster, J.T.M. Amphlett, K.-W. Kim, T. Kerry, K. Lee, C.A. Sharrad, SOHIO process legacy waste treatment: uranium recovery using ion exchange, J. Ind. Eng. Chem. 81 (2020) 144-152, https://doi.org/10.1016/j.jiec.2019.09.001.

[22] A.M. Masoud, Sorption behavior of uranium from sulfate media using purolite A400 as a strong base anion exchange resin, Int. J. Environ. Anal. Chem. (2020), https://doi.org/10.1080/03067319.2020.1763974.

[23] M.F. Hamza, A. Gamal, G. Hussein, M.S. Nagar, A.A.H. Abdel-Rahman, Y. Wei, E. Guibal, Uranium(VI) and zirconium(IV) sorption on magnetic chitosan derivatives - effect of different functional groups on separation properties, J. Chem Technol. Biotechnol. 94 (2019) 3866-3882, https://doi.org/10.1002/jctb.6185.

[24] M.L. Rahman, M.S. Sarjadi, S.E. Arshad, M.M. Yusoff, S.M. Sarkar, B. Musta, Kena cellulose-based poly(amidoxime) ligand for adsorption of rare earth ions, Rare Met. 38 (2019) 259-269, https://doi.org/10.1007/s12598-018-1061-7.

[25] D.X. He, N. Tan, X.M. Luo, X.C. Yang, K. Ji, J.W. Han, C. Chen, Y.Q. Liu, Preparation, uranium (VI) absorption and reuseability of marine fungus mycelium modified by the bis-amidoxime-based groups, Radiochim. Acta 108 (2020) 37-49, https://doi.org/10.1515/ract-2018-3063.

[26] M.F. Hamza, A.E. Mubark, Y. Wei, T. Vincent, E. Guibal, Quaternization of composite algal/PEI beads for enhanced uranium sorption-application to ore acidic leachate, Gels 6 (2020), 6020012, https://doi.org/10.3390/gels6020012.

[27] H. Sarafraz, A. Minuchehr, G. Alahyarizadeh, Z. Rahimi, Synthesis of enhanced phosphonic functional groups mesoporous silica for uranium selective adsorption from aqueous solutions, Sci. Rep. 7 (2017), 11675, https://doi.org/10.1038/ s41598-017-11993-5.

[28] X. Heres, V. Blet, P. Di Natale, A. Ouaattou, H. Mazouz, D. Dhiba, F. Cuer, Selective extraction of rare earth elements from phosphoric acid by ion exchange resins, Metals 8 (2018), 8090682, https://doi.org/10.3390/met8090682.

[29] A.A. Galhoum, Facile synthesis of functionalized polyglycidylmethacrylatemagnetic nanocomposites for enhanced uranium sorption, RSC Adv. 9 (2019) 38783-38796.

[30] C.E. Duval, W.A. Hardy, S. Pellizzeri, T.A. DeVol, S.M. Husson, Phosphonic acid and alkyl phosphate-derivatized resins for the simultaneous concentration and detection of uranium in environmental waters, React. Funct. Polym. 137 (2019) 133-139, https://doi.org/10.1016/j.reactfunctpolym.2019.01.015.

[31] B. Maranescu, L. Lupa, A. Visa, Synthesis, characterization and rare earth elements adsorption properties of phosphonate metal organic frameworks, Appl. Surf. Sci. 481 (2019) 83-91, https://doi.org/10.1016/j.apsusc.2019.03.067.

[32] E.V. Abaldueva, T.V. Druzhinina, Sorption of heavy metals by polyamide chemisorption fibre, Fibre Chem. 36 (2004) 33-36, https://doi.org/10.1023/b: Fich.0000025536.01642.02.

[33] V. Thangaraj, K. Aravamudan, R. Lingam, S. Subramanian, Individual and simultaneous adsorption of Ni (II), Cd (II), and Zn (II) ions over polyamide resin: equilibrium, kinetic and thermodynamic studies, Environ. Prog. Sustain. Energy 38 (2019) S340-S351, https://doi.org/10.1002/ep.13056.

[34] E.A. Haggag, A.A. Abdelsamad, A.M. Masoud, Potentiality of uranium extraction from acidic leach liquor by polyacrylamide-acrylic acid titanium silicate composite adsorbent, Int. J. Environ. Anal. Chem. (2019) 204-224, https://doi.org/10.1080/ 03067319.2019.1636037.

[35] M.A. Alheety, A. Raoof, S.A. Al-Jibori, A. Karadă̆, A.I. Khaleel, H. Akbaş, O. Uzun, Eco-friendly $\mathrm{C}_{60}$-SESMP-Fe $\mathrm{S}_{3} \mathrm{O}_{4}$ inorganic magnetizable nanocomposite as highperformance adsorbent for magnetic removal of arsenic from crude oil and water samples, Mater. Chem. Phys. 231 (2019) 292-300, https://doi.org/10.1016/j. matchemphys.2019.04.040.

[36] A.R. Mahmood, I.Q. Abdallah, M.A. Alheety, H. Akbaş, A. Karadă̆, N, O-rich graphene oxide based eggshell membrane polymer: Preparation, characterization and its utility as nano sorbent for solid phase extraction of $\mathrm{Pb}$ (II) in various water samples, AIP Conf. Proc. 2144 (1) (2019), 020003, https://doi.org/10.1063/ 1.5123060.

[37] T.C. Dietz, C.E. Tomaszewski, Z. Tsinas, D. Poster, A. Barkatt, M. Adel-Hadadi, F B. Bateman, L.T. Cumberland, E. Schneider, K. Gaskell, et al., Uranium removal from seawater by means of polyamide 6 fibers directly grafted with diallyl oxalate through a single-step, solvent-free irradiation process, Ind. Eng. Chem. Res. 55 (2016) 4179-4186, https://doi.org/10.1021/acs.iecr.5b03401.

[38] H. Javadian, M. Ruiz, M. Taghavi, A.M. Sastre, Synthesis of magnetic CMC bionanocomposite containing a novel biodegradable nanoporous polyamide selectively synthesized in ionic liquid as green media: investigation on $\mathrm{Nd}^{+3}, \mathrm{~Tb}^{+3}$ and $\mathrm{Dy}^{+3}$ rare earth elements adsorption, J. Mol. Liq. 308 (2020), 113017, https:// doi.org/10.1016/j.molliq.2020.113017.

[39] S.A. Chattanathan, T.P. Clement, S.R. Kanel, M.O. Barnett, N. Chatakondi, Remediation of uranium-contaminated groundwater by sorption onto hydroxyapatite derived from catfish bones, Water Air Soil Pollut. 224 (2013) 1429-1437, https://doi.org/10.1007/s11270-012-1429-5.

[40] A.M. Osman, A.H. Hendi, T.A. Saleh, Simultaneous adsorption of dye and toxic metal ions using an interfacially polymerized silica/polyamide nanocomposite: kinetic and thermodynamic studies, J. Mol. Liq. 314 (2020), 113640, https://doi org/10.1016/j.molliq.2020.113640.

[41] X.H. Liu, Q.J. Wu, L.A. Berglund, H. Lindberg, J.Q. Fan, Z.N. Qi, Polyamide 6/clay nanocomposites using a cointercalation organophilic clay via melt compounding, J. Appl. Polym. Sci. 88 (2003) 953-958, https://doi.org/10.1002/app.12031.

[42] M.F. Cheira, M.N. Kouraim, I.H. Zidan, W.S. Mohamed, T.F. Hassanein, Adsorption of U(VI) from sulfate solution using montmorillonite/polyamide and nano-titanium oxide/polyamide nanocomposites, J. Environ. Chem. Eng. 8 (2020), 104427, https://doi.org/10.1016/j.jece.2020.104427.

[43] T.A. Saleh, I. Ali, Synthesis of polyamide grafted carbon microspheres for removal of rhodamine B dye and heavy metals, J. Environ. Chem. Eng. 6 (2018) 5361-5368, https://doi.org/10.1016/j.jece.2018.08.033.
[44] T. Godjevargova, S. Mihova, Adsorption of copper on specifically modified polyamide sorbent, J. Appl. Polym. Sci. 90 (2003) 80-85, https://doi.org/ 10.1002/app.12539.

[45] M. Dinari, A. Haghighi, Efficient removal of hexavalent chromium and lead from aqueous solutions by s-triazine containing nanoporous polyamide, Polym. Adv. Technol. 28 (2017) 1683-1689, https://doi.org/10.1002/pat.4040.

[46] L. Ravikumar, S.S. Kalaivani, A. Murugesan, T. Vidhyadevi, G. Karthik, S. D. Kirupha, S. Sivanesan, Synthesis, characterization, and heavy metal ion adsorption studies of polyamides, polythioamides having pendent chlorobenzylidine rings, J. Appl. Polym. Sci. 122 (2011) 1634-1642, https://doi. org/10.1002/app.33968.

[47] A.A. Santiago, A. Ibarra-Palos, J.A. Cruz-Morales, J.M. Sierra, M. Abatal, I. Alfonso, J. Vargas, Synthesis, characterization, and heavy metal adsorption properties of sulfonated aromatic polyamides, High Perform. Polym. 30 (2018) 591-601, https://doi.org/10.1177/0954008317711233.

[48] T. Vidhyadevi, M. Arukkani, K. Selvaraj, P.M. Periyaraman, R. Lingam, S. Subramanian, A study on the removal of heavy metals and anionic dyes from aqueous solution by amorphous polyamide resin containing chlorobenzalimine and thioamide as chelating groups, Korean J. Chem. Eng. 32 (2015) 650-660, https:// doi.org/10.1007/s11814-014-0276-Z.

[49] M.H. Su, D.C.W. Tsang, X.Y. Ren, Q.P. Shi, J.F. Tang, H.G. Zhang, L.J. Kong, L. A. Hou, G. Song, D.Y. Chen, Removal of U(VI) from nuclear mining effluent by porous hydroxyapatite: evaluation on characteristics, mechanisms and performance, Environ. Pollut 254 (2019), 112891, https://doi.org/10.1016/j. envpol.2019.07.059.

[50] I.A. Neacsu, A.E. Stoica, B.S. Vasile, E. Andronescu, Luminescent hydroxyapatite doped with rare earth elements for biomedical applications, Nanomaterials 9 (2019), 9020239, https://doi.org/10.3390/nano9020239.

[51] M.A. Attia, S.I. Moussa, R.R. Sheha, H.H. Someda, E.A. Saad, Hydroxyapatite/ $\mathrm{NiFe}_{2} \mathrm{O}_{4}$ superparamagnetic composite: facile synthesis and adsorption of rare elements, Appl. Radiat. Isot. 145 (2019) 85-94, https://doi.org/10.1016/j. apradiso.2018.12.003.

[52] C. Gok, Neodymium and samarium recovery by magnetic nano-hydroxyapatite, J. Radioanal. Nucl. Chem. 301 (2014) 641-651, https://doi.org/10.1007/s10967014-3193-z.

[53] A. Yasukawa, K. Kandori, H. Tanaka, K. Gotoh, Preparation and structure of carbonated calcium hydroxyapatite substituted with heavy rare earth ions, Mater. Res. Bull. 47 (2012) 1257-1263, https://doi.org/10.1016/j. materresbull.2012.01.018.

[54] A. Yasukawa, K. Gotoh, H. Tanaka, K. Kandori, Preparation and structure of calcium hydroxyapatite substituted with light rare earth ions, Colloids Surf. A 393 (2012) 53-59, https://doi.org/10.1016/j.colsurfa.2011.10.024.

[55] X. Han, Y. Zhang, L. Li, R. Han, G. Wang, W. Wei, Nanosized hydroxyapatite supported on natural sepiolite: a novel adsorbent for Cd(II) removal from simulated groundwater, Mater. Res. Express 6 (2019), 125518, https://doi.org/ 10.1088/2053-1591/ab58ff.

[56] S. Saha, H. Basu, S. Rout, M.V. Pimple, R.K. Singhal, Nano-hydroxyapatite coated activated carbon impregnated alginate: a new hybrid sorbent for uranium removal from potable water, J. Environ. Chem. Eng. 8 (2020), https://doi.org/10.1016/j. jece.2020.103999.

[57] K. Li, S.C. Tjong, Structure, mechanical and bioactive behaviors of polyamide 6/ hydroxyapatite nanocomposites, in: 2010 3rd International Nanoelectronics Conference (INEC), Hong Kong, 2010, pp. 1403-1404, https://doi.org/10.1109/ INEC.2010.5424825.

[58] L. Li, G. Yang, Synthesis and properties of hydroxyapatite nanorod-reinforced polyamide 6 nanocomposites, Polym. Int. 58 (2009) 380-387, https://doi.org/ 10.1002/pi.2542.

[59] L. Li, G. Yang, In situ synthesis of bone-like hydroxyapatite/polyamide 6 nanocomposites, Polym. Int. 57 (2008) 1226-1234, https://doi.org/10.1002/ pi. 2466.

[60] L. Cheng, Y. Li, Y. Zuo, J. Li, H. Wang, Nano-hydroxyapatite/polyamide 6 scaffold as potential tissue engineered bone substitutes, Mater. Res. Innovations 12 (2008) 192-199, https://doi.org/10.1179/143307508x362837.

[61] D. Menon, K.A. Anand, V.C. Anitha, S. Nair, Hydroxyapatite-reinforced polyamide 6,6 nanocomposites through melt compounding, Int. J. Polym. Mater. 59 (2010) 498-509, https://doi.org/10.1080/00914031003627262.

[62] M. Raji, A. el Kacem Qaiss, R. Bouhfid, Effects of bleaching and functionalization of kaolinite on the mechanical and thermal properties of polyamide 6 nanocomposites, RSC Adv. 10 (2020) 4916-4926, https://doi.org/10.1039/ c9ra10579d.

[63] S. Kango, S. Kalia, A. Celli, J. Njuguna, Y. Habibi, R. Kumar, Surface modification of inorganic nanoparticles for development of organic-inorganic nanocomposites-a review, Prog. Polym. Sci. 38 (2013) 1232-1261, https://doi.org/10.1016/j. progpolymsci.2013.02.003.

[64] Y. Zuo, Y.B. Li, J.D. Li, X. Zhang, H.B. Liao, Y.Y. Wang, W.H. Yang, Novel biocomposite of hydroxyapatite reinforced polyamide and polyethylene: composition and properties, Mater. Sci. Eng. A 452 (2007) 512-517, https://doi.org/10.1016/j. msea.2006.11.138.

[65] M.V. Lopez-Ramon, F. Stoeckli, C. Moreno-Castilla, F. Carrasco-Marin, On the characterization of acidic and basic surface sites on carbons by various techniques, Carbon 37 (1999) 1215-1221, https://doi.org/10.1016/s0008-6223(98)00317-0.

[66] Y.M. Khawassek, M.H. Taha, Kinetics of leaching process of sella uranium ore material, South Eastern Desert, Egypt, Nucl. Sci. Sci. J. 2 (2013) 175-182, https:// doi.org/10.21608/nssj.2013.30993.

[67] NMA, "El Sela Development Project", Internal Report, Nuclear Materials Authority, Cairo, Egypt, 2011. 
[68] Z. Marczenko, M. Balcerzak, Chapter 39 - rare-earth elements, in: Z. Marczenko, M. Balcerzak (Eds.), Analytical Spectroscopy Library, Elsevier, 2000, pp. 341-349.

[69] Z. Marczenko, M. Balcerzak, Chapter 37 - phosphorus, in: Z. Marczenko, M. Balcerzak (Eds.), Analytical Spectroscopy Library, Elsevier, 2000, pp. 326-333.

[70] APHA, Standard Methods for the Examination of Water and Wastewater, 23th ed. ed., American Public Health Association, Amercian Water Works Association, Water Environment Federation, Washington, DC, USA, 2017.

[71] Y. Yan, F. Qi, S. Zhao, Y. Luo, S. Gu, Q. Li, L. Zhang, S. Zhou, N. Bolan, A new lowcost hydroxyapatite for efficient immobilization of lead, J. Colloid Interface Sci. 553 (2019) 798-804, https://doi.org/10.1016/j.jcis.2019.06.090.

[72] X. Xia, J. Shen, F. Cao, C.J. Wang, M. Tang, Q.Y. Zhang, S.S. Wei, A facile synthesis of hydroxyapatite for effective removal strontium ion, J. Hazard. Mater. 368 (2019) 326-335, https://doi.org/10.1016/j.jhazmat.2019.01.040.

[73] P. Ni, J.T. Fox, Synthesis and appraisal of a hydroxyapatite/pectin hybrid materia for zinc removal from water, RSC Adv. 9 (2019) 21095-21105, https://doi.org/ 10.1039/c9ra03710a.

[74] H. Zhao, W. Kang, X. Ma, N. Deng, Z. Li, B. Cheng, Fabrication and catalytic behavior of hierarchically-structured nylon 6 nanofiber membrane decorated with silver nanoparticles, Chin. J. Catal. 38 (2017) 73-82, https://doi.org/10.1016/ S1872-2067(16)62545-7.

[75] M. Mehrabanian, M. Nasr-Esfahani, HA/nylon 6., 6 porous scaffolds fabricated by salt-leaching/solvent casting technique: effect of nano-sized filler content on scaffold properties, Int. J. Nanomed. 6 (2011) 1651-1659, https://doi.org/ 10.2147/ijn.S21203.

[76] X. Zhang, Y.B. Li, G.Y. Lv, Y. Zuo, Y.H. Mu, Thermal and crystallization studies of nano-hydroxyapatite reinforced polyamide 66 biocomposites, Polym. Degrad. Stab. 91 (2006) 1202-1207, https://doi.org/10.1016/j.polymdegradstab.2005.02.006.

[77] X. Zhang, Y.B. Li, Y. Zuo, G.Y. Lv, Y.H. Mu, H. Li, Morphology, hydrogen-bonding and crystallinity of nano-hydroxyapatite/polyamide 66 biocomposites, Compos. Part A 38 (2007) 843-848, https://doi.org/10.1016/j.compositesa.2006.08.002.

[78] L.I. Castelan-Velazco, J. Mendez-Nonell, S. Sanchez-Valdes, L.F. Ramos-deValle, Morphology and osteogenetic characteristics of polyamide/nanohydroxyapatite biocomposites, Polym. Bull. 62 (2009) 99-110, https://doi.org/10.1007/s00289008-1014-7.

[79] T. Rahim, A.M. Abdullah, H.M. Akil, D. Mohamad, Z.A. Rajion, The improvement of mechanical and thermal properties of polyamide 12 3D printed parts by fused deposition modelling, Express Polym. Lett. 11 (2017) 963-982, https://doi.org/ 10.3144/expresspolymlett.2017.92.

[80] W. Janusz, E. Skwarek, Study of sorption processes of strontium on the synthetic hydroxyapatite, Adsorption (J. Int. Ads. Soc.) 22 (2016) 697-706, https://doi.org/ 10.1007/s10450-016-9761-5.

[81] H. Jensen, K.D. Joensen, J.E. Jørgensen, J.S. Pedersen, E.G. Søgaard, Characterization of nanosized partly crystalline photocatalysts, J. Nanopart. Res. 6 (2004) 519-526, https://doi.org/10.1007/s11051-004-1714-3.

[82] S. Rahavi, A. Monshi, R. Emadi, A. Doostmohammadi, H. Akbarian, Determination of crystallite size in synthetic and natural hydroxyapatite: a comparison between XRD and TEM results, Adv. Mat. Res. 620 (2013) 28-34, https://doi.org/10.4028/ www.scientific.net/AMR.620.28.

[83] J.P. Gustafsson, Visual MINTEQ. KTH, Royal Institute of Technology, Stockholm, Sweden, 2013.

[84] H. Rho, J. Cho, P. Westerhoff, K. Chon, Intrinsic $\mathrm{pK}_{\mathrm{a}}$ of nanofiltration membrane surfaces to assess fouling and cleaning behaviors induced by foulant-membrane electrostatic interactions, Environ. Sci. Technol. 54 (2020) 7706-7714, https://doi. org/10.1021/acs.est.0c01846.

[85] Y. Marcus, Ion Properties, Marcel Dekker, Inc., New York, NY, 1997, p. 259.

[86] N.D. Koone, J.D. Guo, T.W. Zerda, Diffusion of $\mathrm{Er}^{3+}$ in porous sol-gel glass, J. NonCryst. Solids 211 (1997) 150-157, https://doi.org/10.1016/s0022-3093(96) 00610-2.

[87] K.L. Nguyen, V. Wernert, A.M. Lopes, L. Sorbier, R. Denoyel, Effect of tortuosity on diffusion of polystyrenes through chromatographic columns filled with fully porous and porous -shell particles and monoliths, Microporous Mesoporous Mater. 293 (2020), 109776, https://doi.org/10.1016/j.micromeso.2019.109776.

[88] I. Persson, Hydrated metal ions in aqueous solution: how regular are their structures? Pure Appl. Chem. 82 (2010) 1901-1917, https://doi.org/10.1351/paccon-09-10-22.

[89] R.G. Pearson, Acids and bases, Science (New York, N.Y.) 151 (1966) 172-177, https://doi.org/10.1126/science.151.3707.172.

[90] R.G. Silva, C.A. Morais, L.V. Teixeira, É.D. Oliveira, Selective precipitation of highquality rare earth oxalates or carbonates from a purified sulfuric liquor containing soluble impurities, Min. Metall. Explor. 36 (2019) 967-977, https://doi.org/ 10.1007/s42461-019-0090-6. 